University of Nebraska - Lincoln

DigitalCommons@University of Nebraska - Lincoln

Faculty Publications - Chemistry Department Published Research - Department of Chemistry

8-2010

\title{
Photomediated Synthesis of Silver Triangular Bipyramids and Prisms: The Effect of $\mathrm{pH}$ and BSPP
}

Jian Zhang

University of Nebraska-Lincoln, jzhang3@unl.edu

Mark R. Langille

Northwestern University, MarkLangille2013@u.northwestern.edu

Chad A. Mirkin

Northwestern University, chadnano@northwestern.edu

Follow this and additional works at: https://digitalcommons.unl.edu/chemfacpub

Part of the Chemistry Commons

Zhang, Jian; Langille, Mark R.; and Mirkin, Chad A., "Photomediated Synthesis of Silver Triangular Bipyramids and Prisms: The Effect of pH and BSPP" (2010). Faculty Publications -- Chemistry Department. 56.

https://digitalcommons.unl.edu/chemfacpub/56

This Article is brought to you for free and open access by the Published Research - Department of Chemistry at DigitalCommons@University of Nebraska - Lincoln. It has been accepted for inclusion in Faculty Publications -Chemistry Department by an authorized administrator of DigitalCommons@University of Nebraska - Lincoln. 


\title{
Photomediated Synthesis of Silver Triangular Bipyramids and Prisms: The Effect of $\mathrm{pH}$ and BSPP
}

\author{
Jian Zhang, Mark R. Langille and Chad A. Mirkin* \\ Department of Chemistry and International Institute for Nanotechnology \\ Northwestern University, 2145 Sheridan Road, Evanston, Illinois 60208 \\ Corresponding author - C. A. Mirkin, chadnano@northwestern.edu
}

\begin{abstract}
The photomediated synthesis of silver right triangular bipyramids and prisms has been studied, and we have determined that $\mathrm{pH}$ and $[\mathrm{BSPP}] /\left[\mathrm{Ag}^{+}\right]$ratio (bis(p-sulfonatophenyl)phenylphosphine, BSPP) finely control the reaction rate and, consequently, the crystal growth pathway and morphology of final products. A fast reaction rate, realized at a high $\mathrm{pH}$ such as 10 or 11 and a $[\mathrm{BSPP}] /\left[\mathrm{Ag}^{+}\right]$ratio close to 1.0, is necessary to synthesize (100)-faceted right triangular bipyramids in high yield by preferential deposition on (111) facets of planar-twinned seeds. A slower reaction rate, which occurs at lower pH or higher $[\mathrm{BSPP}] /\left[\mathrm{Ag}^{+}\right]$ratios, results in preferential deposition on (100) facets of planar-twinned seeds and the formation of nanoparticles possessing a larger surface area defined by (111) facets, such as truncated triangular bipyramids or prisms. BSPP further influences the reaction rate by ensuring a relatively constant concentration of aqueous $\mathrm{Ag}^{+}$. In the absence of BSPP, the aqueous $\left[\mathrm{Ag}^{+}\right]$steadily decreases as it is consumed and results in a continuously decreasing reaction rate, which changes the preferred facet for silver deposition. At the beginning of the reaction, growth on (111) facets almost exclusively occurs and results in the formation of right triangular bipyramids, which only have (100) facets. When the reaction rate is decreased due to the consumption of $\mathrm{Ag}^{+}$through the course of the reaction, the facet deposition preference changes from (111) to (100) and results in the formation of truncated bitetrahedra, with (111) facets, as the predominant product.
\end{abstract}

\section{Introduction}

Noble metal nanoparticles are important materials that are now used extensively in catalysis, ${ }^{1,2}$ biosensing, $^{3}$ therapeutics, ${ }^{4}$ and optics, ${ }^{5,6}$ and at present, there are a variety of synthetic procedures that allow one to control the size of silver, ${ }^{7}$ gold, ${ }^{8}$ and multimetallic ${ }^{9-11}$ structures over the 2-200 nm length scale. The vast majority of work in this area has focused on isotropic structures, but nanoparticle shape substantially influences the chemical and physical properties of such structures, and therefore,

1. Daniel, M. C. and Astruc, D. Chem. Rev. 2004, 104, 293

2. Burda, C., Chen, X. B., Narayanan, R., and El-Sayed, M. A. Chem. Rev. 2005, 105, 1025

3. Rosi, N. L. and Mirkin, C. A. Chem. Rev. 2005, 105, 1547

4. Rosi, N. L., Giljohann, D. A., Thaxton, C. S., Lytton-Jean, A. K. R., Han, M. S., and Mirkin, C. A. Science 2006, 312, 1027

5. Lal, S., Link, S., and Halas, N. J. Nat. Photonics 2007, 1, 641

6. Eustis, S. and El-Sayed, M. A. Chem. Soc. Rev. 2006, 35, 209

7. Wiley, B., Sun, Y. G., Mayers, B., and Xia, Y. N. Chem. - Eur. J. 2005, 11,454

8. Grzelczak, M., Pérez-Juste, J., Mulvaney, P., and Liz-Marzán, L. M. Chem. Soc. Rev. 2008, 37, 1783

9. Habas, S. E., Lee, H. J., Radmilovic, V., Somorjai, G. A., and Yang, P. D. Nat. Mater. 2007, 6, 692

10. Fan, F. R., Liu, D. Y., Wu, Y. F., Duan, S., Xie, Z. X., Jiang, Z. Y., and Tian, Z. Q. J. Am. Chem. Soc. 2008, 130, 6949

11. Xue, C., Millstone, J. E., Li, S. Y., and Mirkin, C. A. Angew. Chem., Int. Ed. 2007, 46, 8436

12. Xia, Y. N., Xiong, Y. J., Lim, B. K., and Skrabalak, S. E. Angew. Chem., Int. Ed. 2009, 48, 60

13. Millstone, J. E., Hurst, S. J., Métraux, G. S., Cutler, J. I., and Mirkin, C. A. Small 2009, 5, 646

14. Tao, A. R., Habas, S., and Yang, P. D. Small 2008, 4, 310

15. Sun, Y. G. and Xia, Y. N. Science 2002, 298, 2176 anisotropic structures may become important for many applications. ${ }^{12-14}$ Consequently, synthetic methods have been developed for preparing a wide variety of nanostructures, including cubes, ${ }^{15}$ wires, ${ }^{16}$ rods, ${ }^{17-19}$ octahedra, ${ }^{20,} 21$ decahedra, ${ }^{22,}{ }^{23}$ icosahedra, ${ }^{24}$ and prisms. ${ }^{25-29}$ The majority of such reactions are thermally driven, but light-driven plasmon-mediated reactions are one of the most effective methods for making anisotropic silver nanostructures with control over particle size and architectural parameters. ${ }^{23}$, 27-32 Using spherical silver nanoparticles as seeds, our group discovered the first plasmon-mediated

16. Sun, Y. G., Gates, B., Mayers, B., and Xia, Y. N. Nano Lett. 2002, 2, 165

17. Jana, N. R., Gearheart, L., and Murphy, C. J. Chem. Commun. 2001, 617

18. Pietrobon, B., McEachran, M., and Kitaev, V. ACS Nano 2009, 3, 21

19. Nikoobakht, B. and El-Sayed, M. A. Chem. Mater. 2003, 15, 1957

20. Seo, D. H., Park, J. C., and Song, H. J. J. Am. Chem. Soc. 2006, 128, 14863

21. Li, C. C., Shuford, K. L., Park, Q. H., Cai, W. P., Li, Y., Lee, E. J., and Cho, S. O. Angew. Chem., Int. Ed. 2007, 46, 3264

22. Seo, D. H., Il Yoo, C., Chung, I. S., Park, S. M., Ryu, S., and Song, H. J. J. Phys. Chem. C 2008, 112, 2469

23. Pietrobon, B. and Kitaev, V. Chem. Mater. 2008, 20, 5186

24. Kim, F., Connor, S., Song, H. J., Kuykendall, T., and Yang, P. D. Angew. Chem., Int. Ed. 2004, 43, 3673

25. Métraux, G. S., Cao, Y. C., Jin, R. C., and Mirkin, C. A. Nano Lett. 2003, 3, 519

26. Millstone, J. E., Wei, W., Jones, M. R., Yoo, H. J., and Mirkin, C. A. Nano Lett. 2008, 8, 2526

27. Jin, R. C., Cao, Y. W., Mirkin, C. A., Kelly, K. L., Schatz, G. C., and Zheng, J. G. Science 2001, 294, 1901

28. Jin, R. C., Cao, Y. C., Hao, E. C., Métraux, G. S., Schatz, G. C., and Mirkin, C. A. Nature 2003, 425, 487

29. Xue, C. and Mirkin, C. A. Angew. Chem., Int. Ed. 2007, 46, 2036 


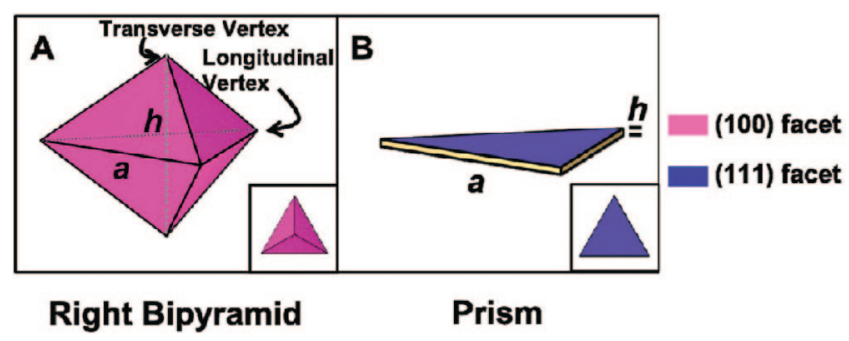

Figure 1. Side views of a right triangular bipyramid (A) and a prism (B) (Inset: top view). The purple and blue colors represent the (100) and (111) facets, respectively.

synthesis of a new class of anisotropic nanostructures called triangular nanoprisms. ${ }^{27}, 33-35$ Under the appropriate conditions, this reaction is highly controllable and efficient, with a sphereto-prism transformation yield of $100 \% .{ }^{29}$ Remarkably, the edge length of the silver nanoprisms can be controlled through the excitation wavelength $\left(\lambda_{\mathrm{ex}}\right)$, with the structures growing until their plasmon resonances are red-shifted from $\lambda_{\mathrm{ex}}{ }^{28,} 29,36$ This method and modified versions of it have been widely utilized for preparing monodisperse samples of triangular silver nanoprisms and plates. ${ }^{11,}$ 29, 37-44 Importantly, plasmon mediated syntheses are not limited to triangular prisms. ${ }^{23,31,32}$ Indeed, we recently showed that plasmon-mediated methods can also be used to prepare monodisperse samples of silver right triangular bipyramids in high yield..$^{30}$ As with the triangular prisms, the edge length of the bipyramids can be controlled exquisitely by adjusting $\lambda_{\text {ex }}{ }^{30}$

A silver right triangular bipyramid, prepared via plasmonmediated or Xia's thermal polyol methods, ${ }^{30,45}$ consists of two right tetrahedra symmetrically joined base-to-base, with six exposed (100) facets. It has two transverse and three longitudinal vertices (Figure 1A), 30, 45 and a twinned (111) plane(s) bisects the entire structure. In contrast, a triangular prism has almost atomically flat (111) facets (Figure 1B) but also contains a twin boundary and/or stacking faults parallel to its (111) triangular faces. From a growth standpoint, these two structures are related: they both grow from planar twinned seeds, ${ }^{12,} 30$, 46 and recently, the transformation of silver nanoprisms into right triangular bipyramids has been reported. ${ }^{47}$

Mechanistic studies of the plasmon-mediated transformation of spherical silver seeds to silver triangular nanoprisms ${ }^{46}$, 48 determined that the process is driven by a series of silver redox cycles. One involves the photochemical reduction of $\mathrm{Ag}^{+}$ by trisodium citrate on the surface of silver nanoparticles un-

30. Zhang, J., Li, S. Z., Wu, J. S., Schatz, G. C., and Mirkin, C. A. Angew. Chem., Int. Ed. 2009, 48, 7787

31. Zhou, J., An, J., Tang, B., Xu, S. P., Cao, Y. X., Zhao, B., Xu, W. Q., Chang, J. J., and Lombardi, J. R. Langmuir 2008, 24, 10407

32. Zheng, X. L., Zhao, X. J., Guo, D. W., Tang, B., Xu, S. P., Zhao, B., Xu, W. Q., and Lombardi, J. R. Langmuir 2009, 25, 3802

33. Metraux, G. S., Jin, R. C., and Mirkin, C. A. Small 2006, 2, 1335

34. Xue, C., Chen, X. D., Hurst, S. J., and Mirkin, C. A. Adv. Mater. 2007, 19, 4071

35. Xue, C., Li, Z., and Mirkin, C. A. Small 2005, 1, 513

36. Maillard, M., Huang, P. R., and Brus, L. Nano Lett. 2003, 3, 1611

37. Rocha, T. C. R., Winnischofer, H., Westphal, E., and Zanchet, D. J. Phys. Chem. C 2007, 111, 2885

38. Zhang, Q., Ge, J. P., Pham, T., Goebl, J., Hu, Y. X., Lu, Z., and Yin, Y. D. Angew. Chem., Int. Ed. 2009, 48, 3516

39. Zheng, X. L., Xu, W. Q., Corredor, C., Xu, S. P., An, J., Zhao, B., and Lombardi, J. R. J. Phys. Chem. C 2007, 111, 14962

40. Tang, B., Xu, S. P., An, J., Zhao, B., and Xu, W. Q. J. Phys. Chem. C $2009,113,7025$ der plasmon excitation, and the second is the oxidative dissolution of small silver nanoparticles by $\mathrm{O}_{2}$, which is facilitated by bis( $p$-sulfonatophenyl)phenylphosphine (BSPP). ${ }^{46,} 48$ BSPP is a water-soluble triarylphosphine that forms coordination complexes with $\mathrm{Ag}^{+}$and, therefore, increases the total concentration of $\mathrm{Ag}^{+}$, including aqueous $\mathrm{Ag}^{+}$and $\mathrm{Ag}^{+}-\mathrm{BSPP}$ complexes. ${ }^{49}, 50$ These reactions continue and favor the growth of the triangular prisms until the surface plasmon resonances of such structures are red-shifted from $\lambda_{\text {ex }}$.

Interestingly, although both polyol and photomediated synthetic methods can yield silver right triangular bipyramids, ${ }^{30,} 45$ there is very little information about the mechanistic bases for these transformations. Herein, we describe one such study for the photomediated growth process. Importantly, we have found that $\mathrm{pH}$ and BSPP concentration play major roles in this reaction. By varying $\mathrm{pH}$ and the molar ratio of $\mathrm{BSPP}$ and $\mathrm{Ag}^{+}$ $\left([\mathrm{BSPP}] /\left[\mathrm{Ag}^{+}\right]\right.$ratio), both triangular bipyramids and nanoprisms can be selectively synthesized. We determined that a high $\mathrm{pH}(>10)$ and a $[\mathrm{BSPP}] /\left[\mathrm{Ag}^{+}\right]$ratio close to 1 are optimum for the synthesis of monodisperse silver right triangular bipyramids. A lower $\mathrm{pH}$ or a higher $[\mathrm{BSPP}] /\left[\mathrm{Ag}^{+}\right]$ratio leads to the formation of nanoparticles with higher aspect ratios, such as truncated triangular bipyramids or prisms. Essentially, the $\mathrm{pH}$ and $[\mathrm{BSPP}] /\left[\mathrm{Ag}^{+}\right]$ratio finely control the rate of silver deposition and particle growth. At faster rates, deposition occurs preferentially on (111) facets as compared with (100) facets. Consequently, under these conditions, planar-twinned seeds having both crystal facets exposed will get converted into (100)-faceted right triangular bipyramids. In control experiments where the rate of deposition is deliberately made slower by lowering the $\mathrm{pH}$ and/or raising the $[\mathrm{BSPP}] /\left[\mathrm{Ag}^{+}\right]$ratio, the deposition occurs preferentially on (100) facets as compared with (111) facets, yielding structures with either a mixture of (100) and (111) facets (truncated bipyramids) or mostly (111) facets (triangular prisms). BSPP influences the reaction rate by ensuring a relatively constant concentration of aqueous $\mathrm{Ag}^{+}$over the entire course of the reaction. This effect is demonstrated in a control experiment where BSPP was excluded. With such conditions, the reaction rate strongly depends on the concentration of free $\mathrm{Ag}^{+}$. This leads to a reaction rate that constantly decreases, initially favoring deposition onto the (111) facets at the early stages of the reaction, producing small (100)-faceted right triangular bipyramids, and then favoring deposition onto (100) facets in the latter half of the reaction producing (111)-faceted truncated bitetrahedra as the predominant final product.

41. Bastys, V., Pastoriza-Santos, I., Rodríguez-González, B., Vaisnoras, R., and Liz-Marzán, L. M. Adv. Funct. Mater. 2006, 16, 766

42. Lee, G. P., Minett, A. I., Innis, P. C., and Wallace, G. G. J. Mater. Chem. 2009, 19, 8294

43. Tang, B., An, J., Zheng, X. L., Xu, S. P., Li, D. M., Zhou, J., Zhao, B., and $\mathrm{Xu}, \mathrm{W}$. Q. J. Phys. Chem. C 2008, 112, 18361

44. An, J., Tang, B., Zheng, X. L., Zhou, J., Dong, F. X., Xu, S. P., Wang, Y., Zhao, B., and Xu, W. Q. J. Phys. Chem. C 2008, 112, 15176

45. Wiley, B. J., Xiong, Y. J., Li, Z. Y., Yin, Y. D., and Xia, Y. N. Nano Lett. 2006, 6, 765

46. Xue, C., Métraux, G. S., Millstone, J. E., and Mirkin, C. A. J. Am. Chem. Soc. 2008, 130, 8337

47. McEachran, M. and Kitaev, V. Chem. Commun. 2008, 5737

48. Wu, X. M., Redmond, P. L., Liu, H. T., Chen, Y. H., Steigerwald, M., and Brus, L. J. Am. Chem. Soc. 2008, 130, 9500

49. Ahrland, S., Chatt, J., Davies, N. R., and Williams, A. A. J. Chem. Soc. 1958, 276

50. Barron, P. F., Dyason, J. C., Healy, P. C., Engelhardt, L. M., Skelton, B. W., and White, A. H. J. Chem. Soc., Dalton Trans. 1986, 1965 


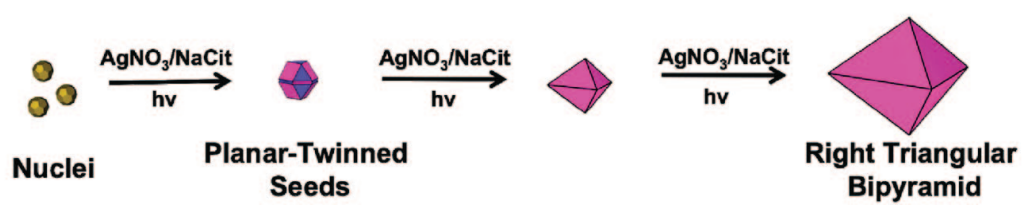

Scheme 1. Proposed Growth Process for Silver Right Triangular Bipyramids from $\mathrm{AgNO}_{3}$ and Spherical Silver Seed Particles

\section{Experimental Section}

Chemicals and Materials - Silver nitrate (99.998\%), trisodium citrate dihydrate $(99.9 \%)$, sodium hydroxide $(99.99 \%)$, and sodium borohydride $(99.99 \%)$ were purchased from Aldrich and used as received. Bis-( $p$-sulfonatophenyl)phenylphosphine dihydrate dipotassium salt (BSPP) was purchased from Strem Chemicals, Inc. All $\mathrm{H}_{2} \mathrm{O}$ was purified with a Barnstead Nanopure water purification system (resistance $=18.1 \mathrm{M} \Omega$ ).

Instrumentation - UV-visible spectra were recorded on a Cary-5000 UV/vis spectrometer. Transmission electron microscopy (TEM) imaging was performed on a Hitachi H8100 transmission electron microscope $(200 \mathrm{kV})$. Scanning electron microscopy (SEM) was performed on a Hitachi S4800-II scanning electron microscope. All of the irradiation experiments were performed with a halogen lamp (Dolan-Jenner, MI-150) as the light source. An optical band-pass filter $(25 \mathrm{~mm}$ diameter, Intor Inc.) centered at $550 \pm 20 \mathrm{~nm}$ was employed to control the irradiation wavelength. The solution $\mathrm{pH}$ value was measured with a $\mathrm{pH}$ meter (Oakton, $\mathrm{pH}$ 510). Inductively Coupled Plasma Optical Emission Spectroscopy (ICP-OES) experiments were performed on a Varian Vista-MPS ICP-OES spectrometer. The CV measurements were carried out in a three-electrode cell using a BAS 100B/W electrochemical analyzer.

Preparation of Silver Nanoparticle Seeds - Silver nanoparticles were prepared according to literature methods. ${ }^{29}$ In a typical synthesis, Nanopure water $(95 \mathrm{~mL}), \mathrm{AgNO}_{3}(0.5 \mathrm{~mL}, 20 \mathrm{mM})$, and trisodium citrate $(1 \mathrm{~mL}, 30 \mathrm{mM})$ were combined in a $250 \mathrm{~mL}$ three-neck flask. The flask was immersed in an ice bath, and the solution was bubbled with $\mathrm{N}_{2}$ under vigorous stirring for $30 \mathrm{~min}$. One $\mathrm{mL}$ of aqueous $\mathrm{NaBH}_{4}(50 \mathrm{mM}$, freshly prepared with icecold Nanopure water prior to use) was rapidly injected into the solution. Over the next $15 \mathrm{~min}, 5$ drops of $\mathrm{NaBH}_{4}$ solution were added every $2 \mathrm{~min}$ into the solution. Then $1 \mathrm{~mL}$ of aqueous BSPP $(5 \mathrm{mM})$ and $1 \mathrm{~mL}$ of $\mathrm{NaBH}_{4}(50 \mathrm{mM})$ were added dropwise and sequentially to the reaction mixture. The resulting Ag colloid was gently stirred for $5 \mathrm{~h}$ in the ice bath and allowed to age overnight at $4{ }^{\circ} \mathrm{C}$ in the dark. These nanoparticles were used as the seeds for the photochemical reactions.

Synthesis of Silver Nanostructures at Different $\mathbf{p H}$ and BSPP Concentration - Nanopure water $(17.0 \mathrm{~mL}), \mathrm{AgNO}_{3}$ $(0.60 \mathrm{~mL}, 10 \mathrm{mM})$, BSPP $(10 \mathrm{mM})$, trisodium citrate $(0.30 \mathrm{~mL}$, $0.10 \mathrm{M}$ ), and $0.50 \mathrm{~mL}$ of $\mathrm{Ag}$ nanoparticles (seeds) were mixed in a $24 \mathrm{~mL}$ glass vial. $0,0.60,0.75,0.90,1.05,1.20$, and $1.35 \mathrm{~mL}$ of BSPP were used to vary the ratio $[\mathrm{BSPP}] /\left[\mathrm{Ag}^{+}\right]$to $0,1.0$, $1.25,1.5,1.75,2.0$, and 2.25 respectively. Then the $\mathrm{pH}$ of the solution was adjusted to $6,7,8,9,10$, and 11 by adding either $\mathrm{HNO}_{3}(0.5 \mathrm{M})$ or $\mathrm{NaOH}(0.1 \mathrm{M})$. The final volume of the reaction solution was $21.0 \mathrm{~mL}$. (Note that the synthetic method used here has been modified in comparison with the original silver bipyramid synthesis. ${ }^{30}$ Silver seed particles were used to normalize the potential difference in nucleation rates for all of the reactions studied.) This solution was then irradiated with a 150-W halogen lamp coupled with an optical band-pass filter $(550 \pm 20 \mathrm{~nm})$. A $1 \mathrm{~cm}$ distance between the lamp and filter was maintained throughout the reaction. The intensity of the lamp was $0.4 \mathrm{~W}$, measured by an optical power meter

(Newport 1916-C) coupled with a thermopile detector (818P010-12) with an active diameter of $12 \mathrm{~mm}$.

\section{Results and Discussion}

A typical synthesis of silver right triangular bipyramids involves irradiating an aqueous solution containing $\mathrm{AgNO}_{3}$, BSPP, trisodium citrate, and sodium hydroxide with visible light. ${ }^{30}$ In prior work, we showed that this reaction takes place in three distinct stages (Scheme 1). ${ }^{30}$ The first stage is the nucleation stage where spherical planar-twinned seed nanoparticles are formed. After these seed particles form, they rapidly grow and are transformed into small bipyramids. In the last stage, the small bipyramids continue to grow into larger bipyramids until all of the available $\mathrm{Ag}^{+}$in solution has been reduced to $\mathrm{Ag}^{0}$. The dominant chemical reaction involved in this synthesis is the reduction of $\mathrm{Ag}^{+}$by trisodium citrate, which is catalyzed by the plasmon excitation of the nanoparticle seeds, similar to the process observed in the plasmon-mediated synthesis of silver triangular nanoprisms..$^{27-29}$ Consistent with this claim, the reaction does not occur in the absence of light or plasmonic seeds. While the mechanism of this reaction is not fully understood at the molecular level, previous studies have demonstrated that the photomediated reaction is governed by two half reactions: (1) the oxidation of citrate and (2) the reduction of $\mathrm{Ag}^{+}$(Figure 2). ${ }^{46,48}$ Because the oxidation of citrate produces $\mathrm{H}^{+}$, this reaction is sensitive to $\mathrm{pH}$. The reduction of $\mathrm{Ag}^{+}$is affected by BSPP concentration because BSPP coordinates to $\mathrm{Ag}^{+}, 49,50$ affecting the aqueous $\mathrm{Ag}^{+}$concentration and, accordingly, the reduction rate. It should be noted that, unlike the photomediated synthesis of silver triangular nanoprisms where $\mathrm{O}_{2}$ is critical for dissolving small silver nanoparticles to generate a source of $\mathrm{Ag}^{+}$for the photoreaction, ${ }^{46} \mathrm{O}_{2}$ is not essential for the synthesis of silver right triangular bipyramids because $\mathrm{AgNO}_{3}$, in the procedure reported herein, provides the necessary $\mathrm{Ag}^{+}$for the reaction. Indeed, silver right bipyramids were also prepared in a control experiment in which the reaction was conducted in the absence of oxygen. Consequently, we have engaged in a systematic study aimed at elucidating the roles of $\mathrm{pH}$ and BSPP in the photoinduced transformation of $\mathrm{AgNO}_{3}$ into right triangular bipyramids.

Photochemical Reactions in the Presence of BSPP - Photochemical reactions at different combinations of $\mathrm{pH}$ and $[\mathrm{BSPP}] /\left[\mathrm{Ag}^{+}\right]$ratio were analyzed to systematically study the

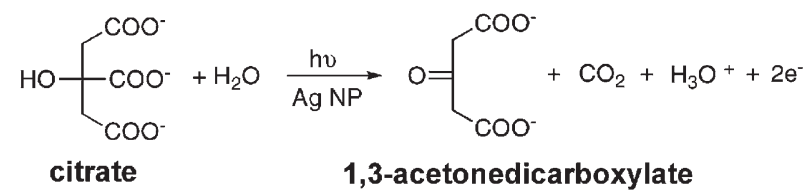

${\mathrm{Ag}-\mathrm{BSPP}_{\mathrm{x}}}^{+}+\mathrm{e}^{-} \longrightarrow \mathrm{Ag}^{0}+\mathrm{xBSPP}$

Figure 2. Chemical half reactions involved in the photochemical synthesis of silver bipyramids. NP = nanoparticle seeds; $x=0,1,2,3$, or 4 based upon ${ }^{31} \mathrm{P}$ NMR spectroscopy (Figure S1 in the Supporting Information) and a comparison to model complexes. ${ }^{49,50}$ 


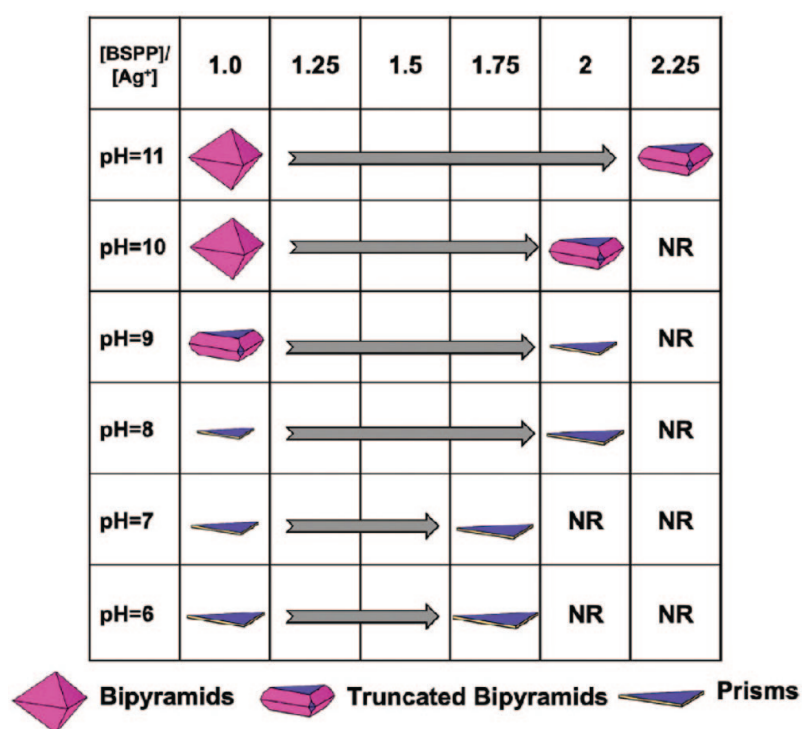

Figure 3. A summary of the relationship between photochemical reaction conditions and resulting product morphology. $\mathrm{NR}=$ no reaction.

role of $\mathrm{pH}$ and BSPP. Six $\mathrm{pH}$ values $(11,10,9,8,7$, and 6$)$ and six $[\mathrm{BSPP}] /\left[\mathrm{Ag}^{+}\right]$ratios $(1.0,1.25,1.5,1.75,2.0$, and 2.25$)$ were evaluated. The morphologies of the reaction products strongly depend on these parameters with specific conditions yielding triangular bipyramids, truncated triangular bipyramids, and nanoprisms (Figures 3 and S2-S7 in the Supporting Information). For example, high $\mathrm{pH}(10$ or 11$)$ and a $[\mathrm{BSPP}] /\left[\mathrm{Ag}^{+}\right]$ratio close to 1.0 yield highly monodisperse (100)-faceted right triangular bipyramids; however, with lower $\mathrm{pH}$ or higher $[\mathrm{BSPP}] /\left[\mathrm{Ag}^{+}\right]$ratios, the shapes of the resulting products vary from truncated bipyramids with both (100) and (111) facets to triangular nanoprisms with mostly (111) facets. The chemical reasons for these shape-directing effects will be discussed below.

Effect of BSPP - We use the aspect ratio to describe the morphology of the synthesized nanoparticles. Here, the aspect ratio is defined as the ratio between the edge length $a$ and the height $h$ of the particles (Figure 1). For bipyramids, edge length $a$ is the side length of the equilateral triangle base.
Height $h$ is the distance between the two transverse vertices in the bipyramids, or the distance between the top and bottom (111) planes in prisms and truncated bipyramids. Consequently, there is a relationship between the aspect ratio and the expected surface facets of a product: as the aspect ratio increases from a right triangular bipyramid to a prism, the ratio of the areas defined by the (111) and (100) facets also increases.

As the $[\mathrm{BSPP}] /\left[\mathrm{Ag}^{+}\right]$ratio increases, the aspect ratio of the resulting nanoparticles increases across all $\mathrm{pH}$ values studied. For example, the original synthesis of right triangular bipyramids is carried out at $\mathrm{pH} 11$ and a $[\mathrm{BSPP}] /\left[\mathrm{Ag}^{+}\right]$ratio of 1.0 (Figure $4 \mathrm{~A}$ ). ${ }^{30} \mathrm{At} \mathrm{pH} 11$, when the $[\mathrm{BSPP}] /\left[\mathrm{Ag}^{+}\right]$ratio is increased to 2.25, the two transverse vertices of the bipyramids become increasingly truncated (Figures $4 \mathrm{~B}, 4 \mathrm{C}$, and S2). With increased BSPP concentrations, product morphologies change from bipyramids to truncated bipyramids at $\mathrm{pH} 10$ (Figure S3), from truncated bipyramids to nanoprisms at $\mathrm{pH} 9$ (Figure S4), and from smaller nanoprisms to larger nanoprisms at $\mathrm{pH} 8,7$, and 6 (Figures S5, S6, and S7). The UV-vis spectra for these reactions are also consistent with the observed change in product morphology (Figure S8). In general, the dipole plasmon resonances of the products red-shifted with increasing $[\mathrm{BSPP}] /\left[\mathrm{Ag}^{+}\right]$ratio and lower $\mathrm{pH}$. This observation is expected because it is known that the dipole plasmon resonance of $\mathrm{Ag}$ nanostructures is highly dependent on the particle aspect ratio. ${ }^{27,51}$ Note that there is a maximum $[\mathrm{BSPP}] /\left[\mathrm{Ag}^{+}\right]$ratio that can be used to synthesize silver nanoparticles at each $\mathrm{pH}$ (Figure 3). This phenomenon is a consequence of the $\mathrm{pH}-$ dependent reducing ability of citrate (citrate is a more powerful reducing agent at higher $\mathrm{pH}$, which leads to faster $\mathrm{Ag}$ deposition (vide infra)). ${ }^{2}$

Effect of $\mathbf{p H}-$ The effect of $\mathrm{pH}$ at fixed [BSPP]/[ $\left.\mathrm{Ag}^{+}\right]$ratios was studied, and it has a marked influence on the particle growth and products observed. For example, at a fixed [BSPP]/ $\left[\mathrm{Ag}^{+}\right]$ratio of 1.0, as the $\mathrm{pH}$ is decreased, the aspect ratio of the product increases (Figure 5A-5C). At $\mathrm{pH} 11$, almost perfectly formed right triangular bipyramids are the predominant product (Figure 5A), while, at $\mathrm{pH}$ 9, truncated bipyramids are the primary product (Figure $5 \mathrm{~B})$. At $\mathrm{pH} 7$, triangular nanoprisms become the major morphology (Figure $5 \mathrm{C}$ ). At $\mathrm{pH}$ values below 6, no reaction is observed due to the dissolution of the $\mathrm{Ag}$ nanoparticle seeds as evidenced by a clear, colorless solution af-

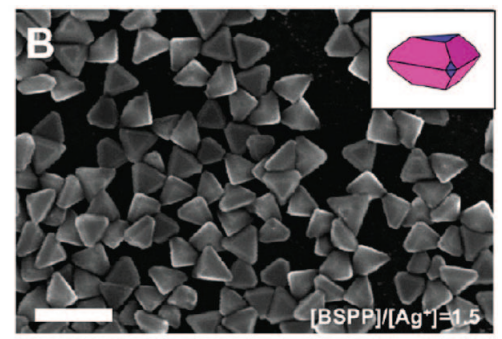

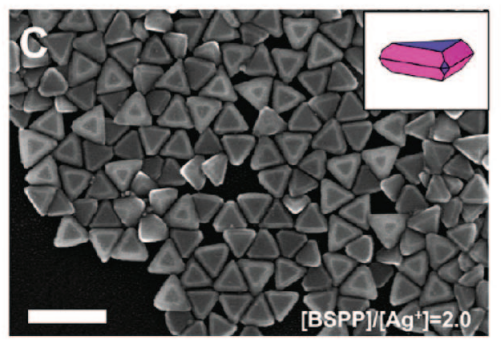

Figure 4. SEM images (scale bar: $200 \mathrm{~nm})$ of the silver nanoparticles synthesized at $\mathrm{pH} 11:(\mathrm{A})[\mathrm{BSPP}] /\left[\mathrm{Ag}^{+}\right]=1.0 ;(\mathrm{B})[\mathrm{BSPP}] /\left[\mathrm{Ag}^{+}\right]=1.5 ;(\mathrm{C})$ $[\mathrm{BSPP}] /\left[\mathrm{Ag}^{+}\right]=2.0$. 

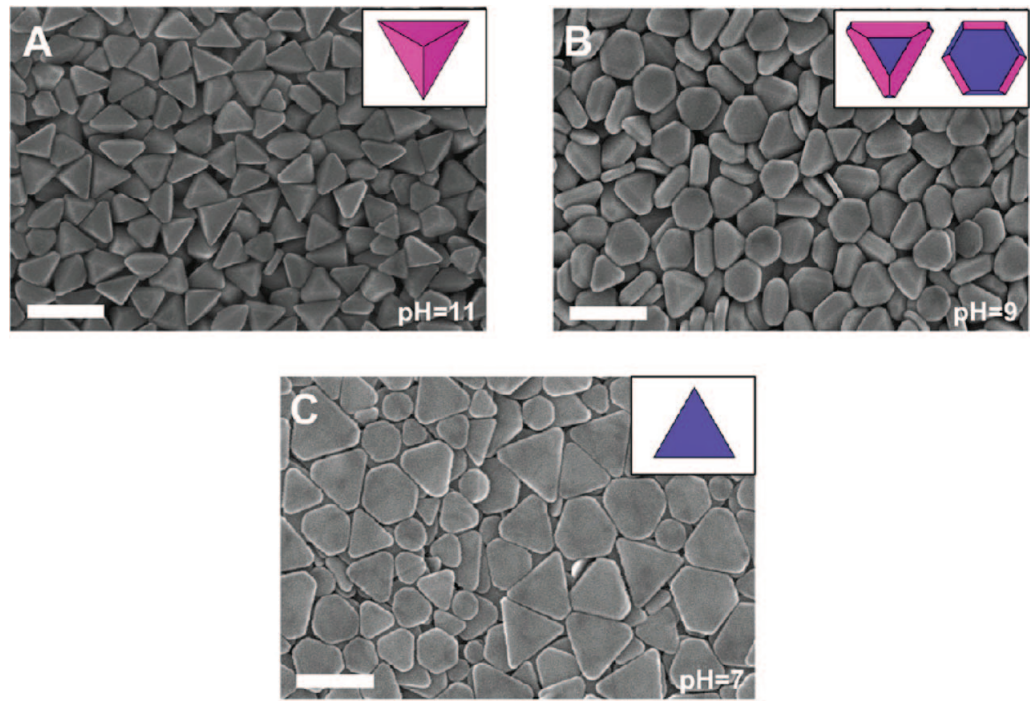

Figure 5. SEM images (scale bar: $200 \mathrm{~nm}$ ) of the silver nanoparticles synthesized at $[\mathrm{BSPP}] /\left[\mathrm{Ag}^{+}\right]=1.0:(\mathrm{A}) \mathrm{pH}=11 ;(\mathrm{B}) \mathrm{pH}=9$; $(\mathrm{C}) \mathrm{pH}=7$.
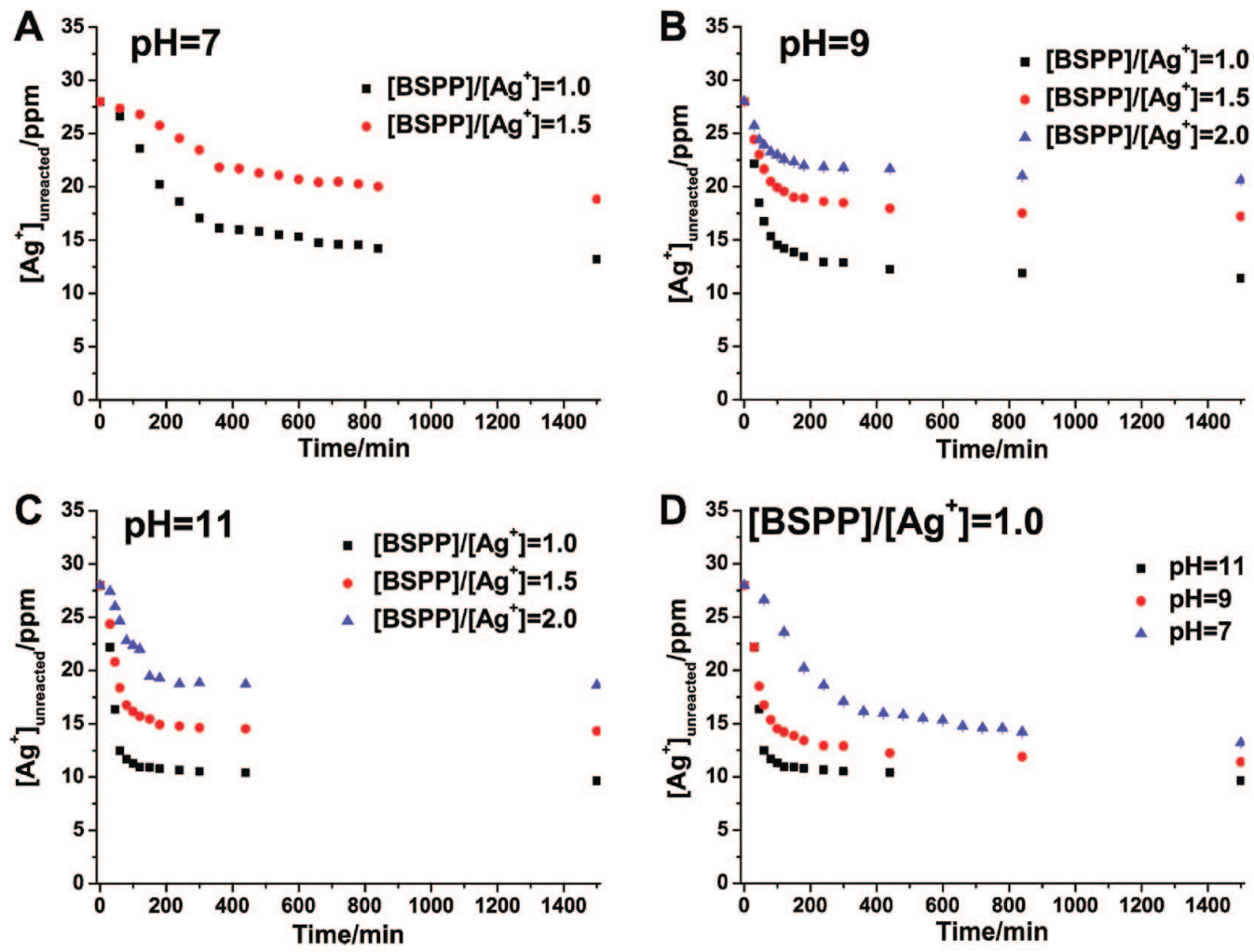

Figure 6. Changes in the concentration of the unreacted $\mathrm{Ag}^{+}$during the reaction carried out at $(\mathrm{A}) \mathrm{pH}=7$; $(\mathrm{B}) \mathrm{pH}=9$; $(\mathrm{C}) \mathrm{pH}=11$; (D) $[\mathrm{BSPP}] /$ $\left[\mathrm{Ag}^{+}\right]=1.0$.

ter irradiation. The reaction also does not occur at $\mathrm{pH} 12$, likely due to the instability of nanoparticles at this $\mathrm{pH}$, as indicated by the observation of a small amount of black precipitate.

Photomediated Reaction Kinetics - To fully understand the growth mechanism of the silver bipyramids and other structures described above, it is necessary to study the kinetics of the photomediated reactions. We used ICP-OES to monitor the concentration of $\mathrm{Ag}^{+}$during the reaction over a $24 \mathrm{~h}$ period of time,

51. Yang, W. H., Schatz, G. C., and Van Duyne, R. P. J. Chem. Phys. $1995,103,869$ at three different $\mathrm{pH}$ values $(11,9$, and 7$)$ as a function of three different $[\mathrm{BSPP}] /\left[\mathrm{Ag}^{+}\right]$ratios $(1.0,1.5$, and 2.0) (Figure 6).

The $[\mathrm{BSPP}] /\left[\mathrm{Ag}^{+}\right]$ratio affects the consumption rate of $\mathrm{Ag}^{+}$ at all three $\mathrm{pH}$ values. In general, as the $[\mathrm{BSPP}] /\left[\mathrm{Ag}^{+}\right]$ratio increases, the rate of $\mathrm{Ag}^{+}$consumption decreases (Figure 6A-6C). This is because BSPP forms coordination complexes with $\mathrm{Ag}^{+}$ in aqueous solution ${ }^{49,50}$ and decreases the concentration of free aqueous $\mathrm{Ag}^{+}$, which results in a decreased reaction rate. Note

52. Honeychurch, K. C., Gilbert, L., and Hart, J. P. Anal. Bioanal. Chem. 2010, 396, 3103 

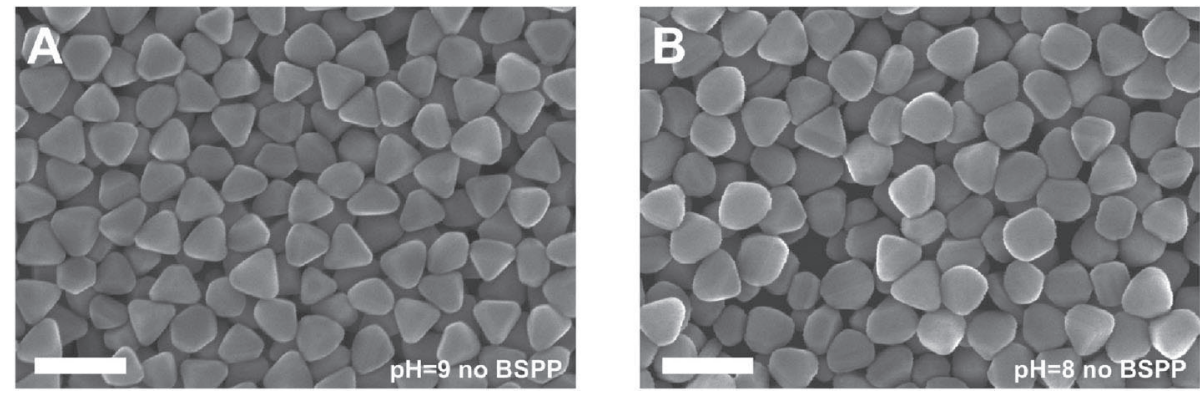

Figure 7. SEM images (scale bar: $200 \mathrm{~nm}$ ) of nanoparticles obtained from reactions 9-0 (A) and 8-0 (B).

that aqueous $\mathrm{Ag}^{+}$is the primary species being reduced. Indeed, electrochemical experiments show that the deposition potential of aqueous $\mathrm{AgNO}_{3}$ is $80 \mathrm{mV}$ more positive than the same solution with an equimolar amount of BSPP (Figure S9).

$\mathrm{pH}$ also strongly affects the rate of $\mathrm{Ag}^{+}$consumption. For example, at a fixed [BSPP]/[ $\left.\mathrm{Ag}^{+}\right]$ratio of 1.0 , the rate of $\mathrm{Ag}^{+}$consumption is faster at $\mathrm{pH} 11$ than at lower $\mathrm{pH}$ values (Figure 6D), which can be explained by the enhanced reducing ability of citrate at higher $\mathrm{pH} .{ }^{52}$ Note that $\mathrm{pH}$ and the $[\mathrm{BSPP}] /\left[\mathrm{Ag}^{+}\right]$ratio also affect the observed final concentration of unreacted $\mathrm{Ag}^{+}$ (after $24 \mathrm{~h}$ ) which is different for each reaction (Figure S10).

Based on the results described above, we conclude that the combination of $\mathrm{pH}$ and [BSPP] modulates the reaction rate and causes different growth modes on the planar twinned seeds. ${ }^{30}$, ${ }^{46}$ A fast reaction rate induces preferential deposition on (111) facets and leads to the formation of (100)-faceted right triangular bipyramids. A slower reaction rate, realized by either raising the $[\mathrm{BSPP}] /\left[\mathrm{Ag}^{+}\right]$ratio or lowering the $\mathrm{pH}$, favors deposition on (100) facets of the planar twinned seeds and generates nanoparticles with higher aspect ratios, such as truncated triangular bipyramids and prisms, possessing a larger surface area defined by (111) facets. This conclusion is also consistent with the observations made for the thermal polyol synthesis of (111)-faceted silver nanoplates. Indeed, these structures were realized by slowing down the $\mathrm{Ag}^{+}$reduction rate by using a weak reducing agent. ${ }^{53,54}$

Reactions in the Absence of BSPP - To further investigate the role of BSPP in the photochemical synthesis of silver bipyramids, a series of control reactions in the absence of BSPP were studied at different $\mathrm{pH}$ values. Reactions at $\mathrm{pH} 11$ or 10 yield a precipitate of $\mathrm{AgOH} / \mathrm{Ag}_{2} \mathrm{O}$ due to the low $\mathrm{K}_{s p}$ of $\mathrm{AgOH}(1.52$ $\left.\times 10^{-8}\right) \cdot{ }^{55}$ Reactions at $\mathrm{pH} 6$ and 7 generate mostly spherical nanoparticles with diameters varying from 10 to $35 \mathrm{~nm}$ (Figure S11), possibly due to the slow reduction rate and poor control over the $\mathrm{Ag}^{+}$concentration (vide infra). For the reaction at $\mathrm{pH} 9$ in the absence of BSPP (hereafter referred to as "reaction 9-0"), the majority of the products are structurally similar to the silver right triangular bipyramids although bound by poorly defined facets (Figure 7A). The reaction at $\mathrm{pH} 8$ in the absence of BSPP (hereafter referred to as "reaction 8-0") generates a significant amount of nanoparticles with a different morphology from either the right triangular bipyramids or other morphologies described above (Figure 7B). Note that nanoparticles with these newly observed morphologies were also present in the product of reaction 9-0, although in lower quantities.

53. Xiong, Y. J., Siekkinen, A. R., Wang, J. G., Yin, Y. D., Kim, M. J., and Xia, Y. N. J. Mater. Chem. 2007, 17, 2600

54. Washio, I., Xiong, Y. J., Yin, Y. D., and Xia, Y. N. Adv. Mater. 2006, 18,1745

55. Lide, D. R. CRC Handbook of Chemistry and Physics, 86th ed.; CRC Press: Boca Raton, FL, 2005.
TEM images of these particles (Figures 8A and S12) also indicate a morphology that is different than a right triangular bipyramid (Figure 8C-D). The diffraction patterns obtained from most of the individual particles in these reactions are characteristic of the [111] zone axis (inset of Figure 8A). With the electron beam perpendicular to the substrate, these results indicate that the particles lie with a (111) facet in contact with the substrate. This new structure was studied with a computer-aided-design (CAD) model and is best described as a structure consisting of two truncated regular tetrahedra (bound with four equilateral triangles) placed base-to-base, with a twinning plane bisecting the entire structure (Figure $8 \mathrm{~B})$. Because all of the faces in this structure are (111) facets, it is structurally distinct from the (100)-faceted right triangular bipyramid.

To confirm the twinned nature of these particles, a series of electron diffraction patterns were taken by tilting a particle inside an electron microscope and changing the relative orientation between the incident electron beam and the particle. The particle was initially aligned along the [111] zone axis, which was set as the zero point (Figure 9A). Two sets of diffraction patterns were observed: one was obtained when the particle was tilted off the [111] zone along the [011] direction by $19.5^{\circ}$ and $-35.3^{\circ}$ to the [211] and [110] zone axes, respectively (Figure $9 \mathrm{~B}$ and $9 \mathrm{C})$; the other set was obtained when the particle was tilled by $19.5^{\circ}, 39.0^{\circ}$, and $-15.8^{\circ}$ to the [211], [111], and

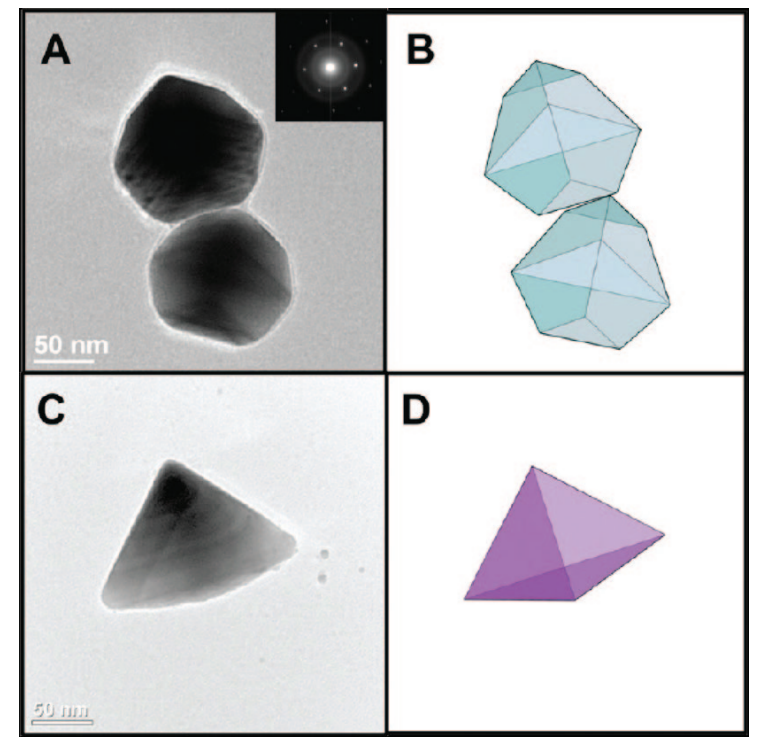

Figure 8. Comparison of silver nanoparticles formed from reaction 8-0 ((A) TEM image and (B) CAD model) and reaction 11-1.0 ((C) TEM image and (D) CAD model). The inset in A shows the electron diffraction pattern obtained from a single particle. 


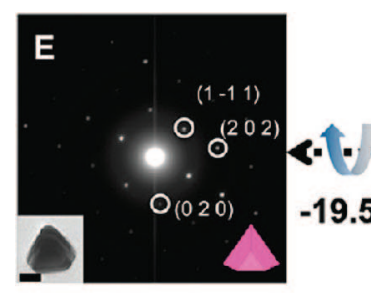

[110]

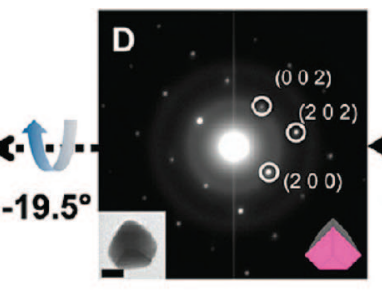

[100]

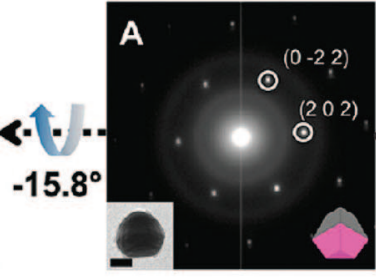

[111]

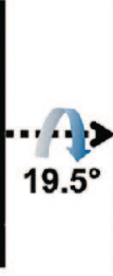

$19.5^{\circ}$

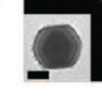

[211]/[211]

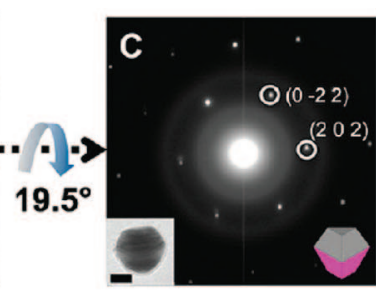

[111]

Figure 9. Selected area electron diffraction (SAED) patterns of a single nanoparticle from reaction 8-0 taken at different incident angles between the electron beam and the particle by tilting along the [011] direction. Positive tilting: A-B-C; negative tilting: A-D-E. Color-coded notation of crystal plane for each SAED pattern indicates the half of the twin crystal responsible for the diffraction pattern.
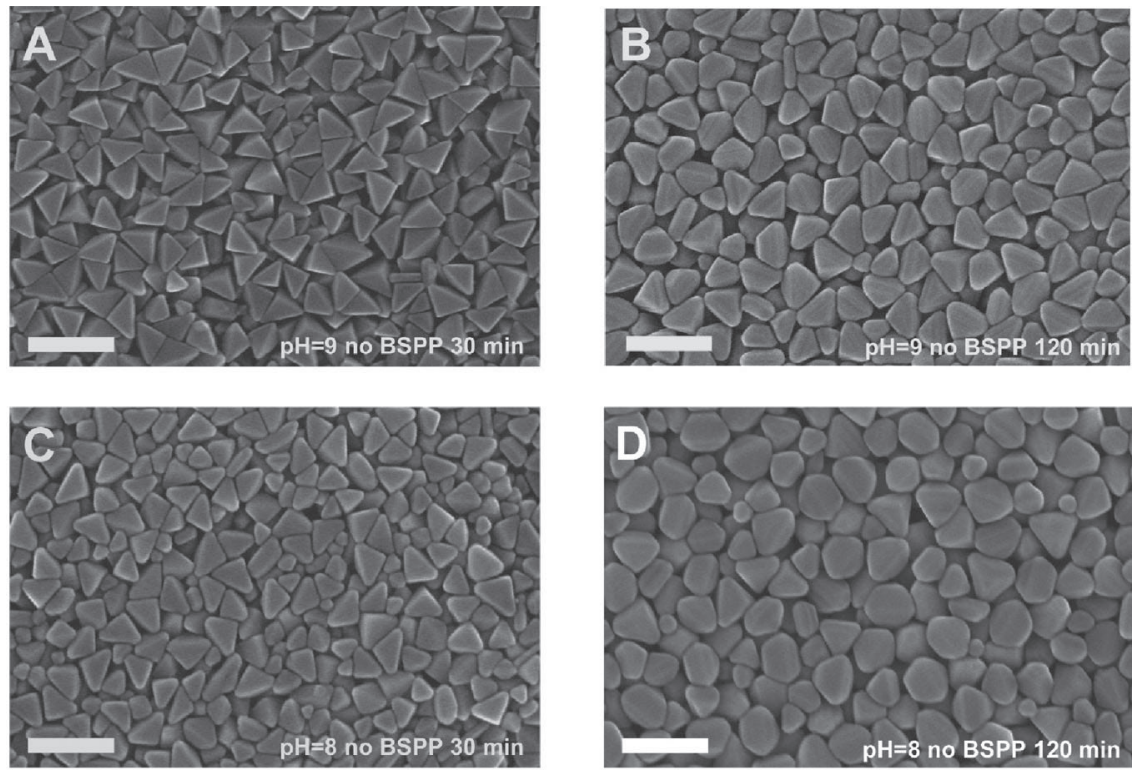

Figure 10. SEM images (scale bar: $200 \mathrm{~nm})$ of the products for reactions $9-0$ and 8-0 at different times: $(\mathrm{A}) \mathrm{pH}=9,30 \mathrm{~min}$; $(\mathrm{B}) \mathrm{pH}=9,120 \mathrm{~min}$; $(\mathrm{C})$ $\mathrm{pH}=8,30 \mathrm{~min}$; (D) $\mathrm{pH}=8,120 \mathrm{~min}$.

[110] zone axes, respectively (Figure 9B, 9D, and 9E). The presence of two sets of diffraction patterns confirms that this particle is a twinned structure. As a result, it has eight (111) facets in total, including six (111) side surface facets and two (111) facets at the top and bottom. This structure is best described as a truncated bitetrahedron.

We used SEM to monitor the growth processes for reactions $9-0$ and 8-0 and compared them with the reaction used to make the right triangular bipyramids $\left(\mathrm{pH} 11,[\mathrm{BSPP}] /\left[\mathrm{Ag}^{+}\right]\right.$ $=1.0$, hereafter referred to as "reaction 11-1.0"). For reaction 9-0, the SEM image taken at $30 \mathrm{~min}$ showed that the majority of the nanoparticles formed are well-faceted right triangular bipyramids (Figure 10A). However, after $120 \mathrm{~min}$ the shape of the nanoparticles had changed significantly: the bipyramids are overgrown and the facets are not well-defined (compare Figures $10 \mathrm{~B}$ and 7A). For reaction $8-0$, a large size distribution of silver right triangular bipyramids was observed after $30 \mathrm{~min}$ (Figure 10C). By $120 \mathrm{~min}$, more well-defined nanoparticles form as the final (111)-faceted truncated bitetrahedra (Figure 10D). These results indicate that the growth pathways for reactions $9-0$ and $8-0$ change as the reactions proceed.

$U V-$ vis spectra measured at different times during the reaction also confirm the nonuniform growth process of the nanoparticles. In the UV-vis spectra used to follow the synthesis of the right triangular bipyramids (reaction 11-1.0, Figure $11 \mathrm{C}$ ), after $30 \mathrm{~min}$ a band appears at $570 \mathrm{~nm}$, indicating the formation of right triangular bipyramids (Figure S13). The intensity of this band continues to increase, and its position slightly blue-shifts until the end of reaction. This observation indicates that the growth of the right triangular bipyramids under these conditions is rather uniform throughout the reaction. In the UV-vis spectra used to follow reactions 9-0 and $8-0$, a band around $570 \mathrm{~nm}$ also appears after $30 \mathrm{~min}$, indicating the formation of right triangular bipyramids, which is consistent with the observations made by SEM (Figure 10A and 10C). However, at $\mathrm{pH} 9$, this band stops increasing after 80 min and then blue-shifts to $520 \mathrm{~nm}$ after $120 \mathrm{~min}$; at $\mathrm{pH}$ 8, this band broadens and becomes nondescript after $60 \mathrm{~min}$. More importantly, an additional band around $500 \mathrm{~nm}$ also appears after 30 and $45 \mathrm{~min}$ in reactions $8-0$ and $9-0$, respectively, and its intensity increases as the two reactions proceed. These observations are indicative of nonuniform growth during both reactions, consistent with the SEM results.

The results from both TEM and UV-vis spectra measured at different reaction time points indicate that the crystal growth pathway changes over the course of the reaction. At the beginning of the reaction, the relatively high concentration of free, aqueous $\mathrm{Ag}^{+}$results in a fast reaction rate and the formation of the (100)-faceted right triangular bipyramids, similar to the regular bipyramid synthesis (reaction 11-1.0). However, as the reaction proceeds, the reduction rate continuously decreases due to the decreasing free $\mathrm{Ag}^{+}$concentration, which affects the crystal growth kinetics: at $\mathrm{pH}$ 9, the decreased reaction rate causes the irregular overgrowth of silver right tri- 

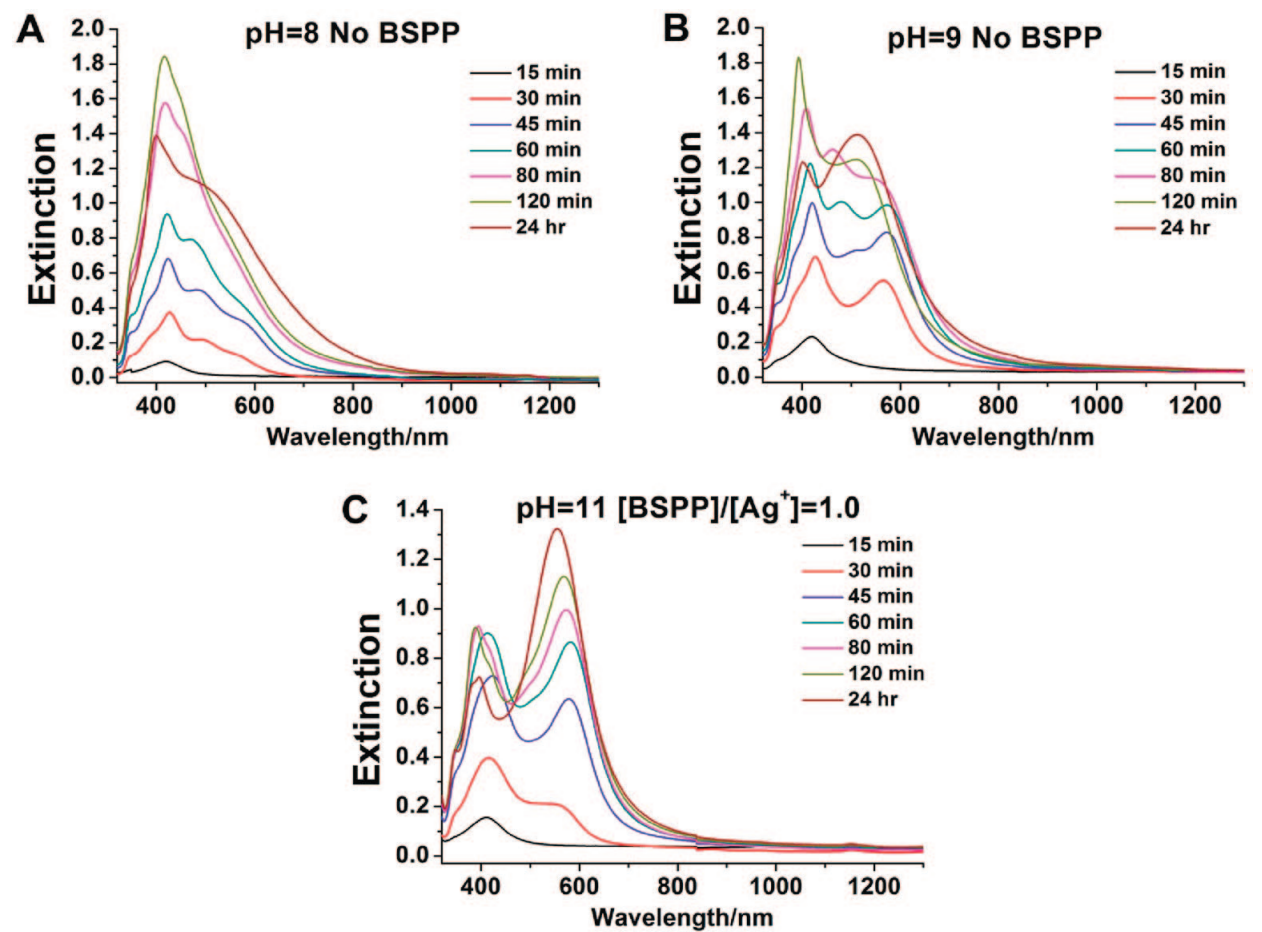

Figure 11. UV-vis spectra measured at different time points for three reactions: $(\mathrm{A}) \mathrm{pH}=8,[\mathrm{BSPP}] /\left[\mathrm{Ag}^{+}\right]=0 ;(\mathrm{B}) \mathrm{pH}=9,[\mathrm{BSPP}] /\left[\mathrm{Ag}^{+}\right]=0$; and (C) $\mathrm{pH}=11,[\mathrm{BSPP}] /\left[\mathrm{Ag}^{+}\right]=1.0$.

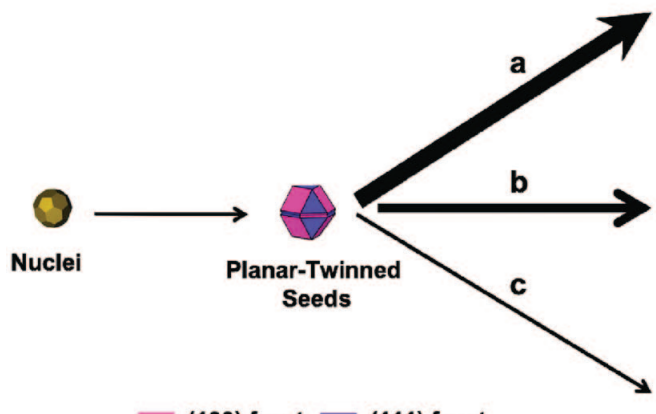

(100) facet (111) facet

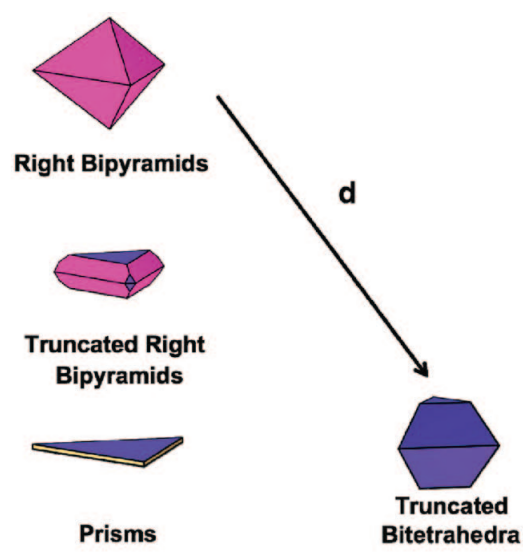

Figure 12. Schematic illustration of the growth pathways for twinned silver nanoparticles seeds. The purple and blue colors represent the (100) and (111) facets, respectively. The thickness of the arrow indicates the relative rates of the reactions with a thicker arrow indicating a faster reaction rate.

angular bipyramids, forming poorly defined surface facets; at $\mathrm{pH} 8$, the decreased rate affects the growth kinetics so significantly that the deposition preference completely switches from the (111) faces to the (100) faces, which generates (111)-faceted truncated bitetrahedra (growth pathway (d) in Figure 12). Indeed, the switching of nanoparticle growth pathways is a common phenomenon in crystal growth. ${ }^{20,56}$ It has also been observed in a polyol synthesis of silver nanoparticles where continued $\mathrm{Ag}^{+}$reduction converts (100)-faceted Ag nanocubes into (111)-faceted Ag octahedra. ${ }^{56}$

Interestingly, the switching of growth pathways is not observed for the reaction 11-1.0. By forming $\mathrm{Ag}^{+}$-BSPP coordination complexes, the aqueous $\left[\mathrm{Ag}^{+}\right]$is significantly decreased and, more importantly, is kept relatively constant over the course of the reaction, as compared to the situation

56. Tao, A., Sinsermsuksakul, P., and Yang, P. D. Angew. Chem., Int. Ed. $2006,45,4597$ where BSPP is absent. The relatively small decrease in aqueous $\left[\mathrm{Ag}^{+}\right]$is not significant enough to affect the reaction rate or the growth pathway.

\section{Conclusions}

Collectively, these data provide a plausible mechanism for understanding the plasmon-mediated synthesis of silver triangular bipyramids and prisms. Notably, we have shown that the $\mathrm{pH}$ and $[\mathrm{BSPP}] /\left[\mathrm{Ag}^{+}\right]$ratio are two important factors which control the reaction rate and, consequently, the crystal growth pathway and final nanoparticle morphology. In general, a fast reaction rate favors the growth of (100)-faceted right triangular bipyramids by preferential Ag deposition on (111) facets compared to (100) facets, which converts the planar-twinned seeds into small right bipyramids bound with (100) facets. The subsequent growth of the small bipyramids leads to the formation of the final right triangular bipyramids. 
A continuous, fast reaction rate throughout the entire growth process of the bipyramids is achieved by a high $\mathrm{pH}(10$ or 11$)$ and a relatively low $[\mathrm{BSPP}] /\left[\mathrm{Ag}^{+}\right]$ratio (close to 1.0).

With a slower reaction rate, the relative deposition preference changes so that the deposition on (100) facets on the planar-twinned seeds begins to dominate, resulting in the formation of nanoparticles bound with a higher percentage of (111) facets, such as truncated triangular bipyramids and prisms. Either increasing the concentration of BSPP ([BSPP] $/\left[\mathrm{Ag}^{+}\right]$ratio) or decreasing the $\mathrm{pH}$ of the reaction can significantly decrease the reaction rate. This observation is consistent with the previous study of the mechanism for the photoinduced conversion of silver nanoparticles into silver nanoprisms, where the reaction rate is limited by the slow oxidative dissolution of the small Ag nanoparticles. ${ }^{46,48}$

Finally, in the absence of BSPP, right triangular bipyramids have been observed as an intermediate product at lower $\mathrm{pH}$ values (e.g., 8 or 9). An initial high concentration of aqueous $\mathrm{Ag}^{+}$is responsible for an initial fast reaction rate and the preferential deposition of Ag onto (111) facets. However, without BSPP, the $\mathrm{Ag}^{+}$concentration steadily decreases and causes the reaction rate to decrease as well. As a result, the crystal growth pathway changes during the growth process, and the Ag is subsequently deposited primarily on (100) facets, forming the (111)-faceted truncated bitetrahedra as the predominant product.

Taken together, this work reveals the intimate relationship between silver triangular bipyramids and nanoprisms and highlights the importance of reaction kinetics in shape-controlled, nanocrystal synthesis.

\section{Acknowledgments}

This work was supported by the MRSEC program of the National Science Foundation at the Material Research Center of Northwestern University. The microscopy work was performed in the EPIC facility of NUANCE Center at Northwestern University. NUANCE Center is supported by NSFNSEC, NSF-MRSEC, Keck Foundation, the State of Illinois, and Northwestern University. J.Z. thanks Mr. Michael J. Wiester for the NMR measurements. C.A.M. is grateful for an NSSEF Fellowship from the DoD.

\section{Supporting Information}

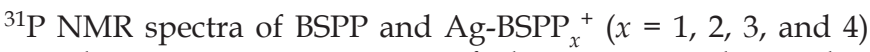
complexes in $\mathrm{D}_{2} \mathrm{O}$; SEM images of silver nanoparticles synthesized at different $\mathrm{pH}$ values and $[\mathrm{BSPP}] /\left[\mathrm{Ag}^{+}\right]$ratios; $\mathrm{UV}-$ vis spectra of the silver nanoparticles synthesized at different $\mathrm{pH}$ values with different $[\mathrm{BSPP}] /\left[\mathrm{Ag}^{+}\right]$ratios; $\mathrm{CV}$ traces of aqueous solution of $\mathrm{AgNO}_{3}$ and a solution containing equimolar of $\mathrm{AgNO}_{3}$ and BSPP; a 3-D representation of the reacted $\mathrm{Ag}^{+}$at different $\mathrm{pH}$ values and $[\mathrm{BSPP}] /\left[\mathrm{Ag}^{+}\right]$ratios; SEM images of the silver nanoparticles synthesized at $\mathrm{pH} 6$ and $\mathrm{pH} 7$ without BSPP; TEM images of truncated bitetrahedra synthesized from reaction 8-0; and SEM images of the silver nanoparticles synthesized in $30 \mathrm{~min}$ for reaction 11-1.0 is presented in the following pages. 
Supporting Information for

Photomediated Synthesis of Silver Triangular Bipyramids and Prisms: The Effect of pH and BSPP

Jian Zhang, Mark R. Langille, and Chad A. Mirkin*

Department of Chemistry and International Institute for Nanotechnology, Northwestern University, 2145 Sheridan Road, Evanston, IL 60208, E-mail: chadnano@northwestern.edu

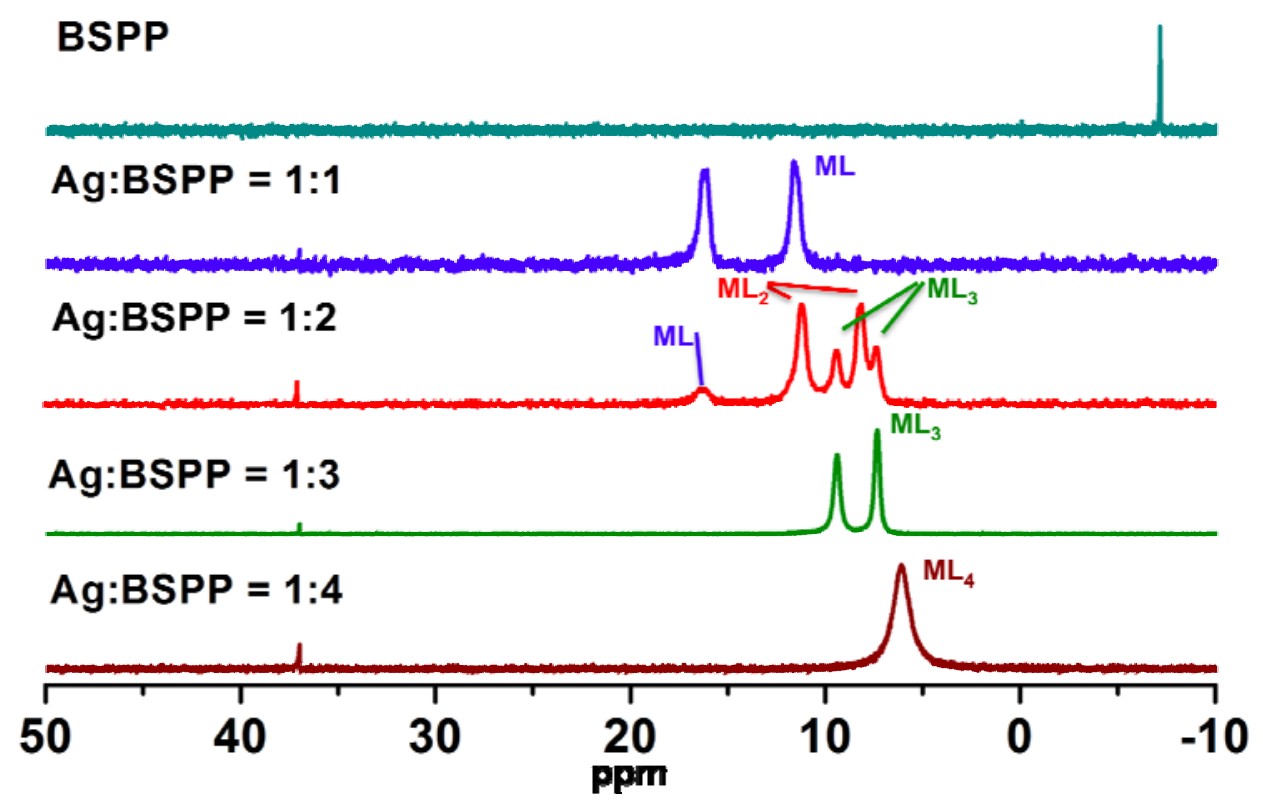

Figure S1. ${ }^{31} \mathrm{P}$ NMR spectra of BSPP and $\operatorname{Ag}_{-B_{S P P}}{ }^{+}\left(x=1,2,3\right.$, and 4) complexes in $\mathrm{D}_{2} \mathrm{O}$. 

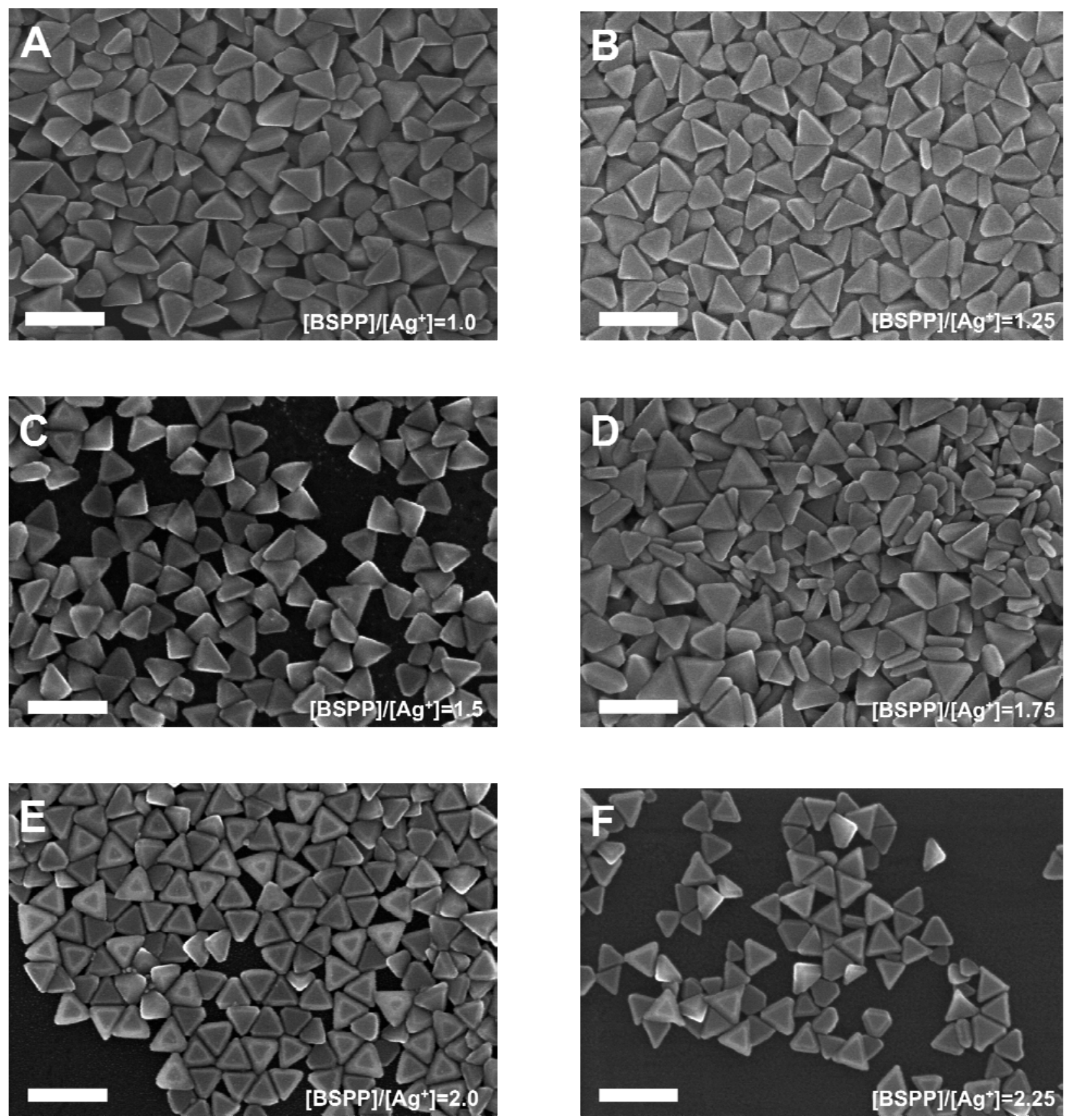

Figure S2. SEM images (scale bar: $200 \mathrm{~nm}$ ) of the silver nanoparticles synthesized at $\mathrm{pH} 11$ with different $[\mathrm{BSPP}] /\left[\mathrm{Ag}^{+}\right]$ratios. 

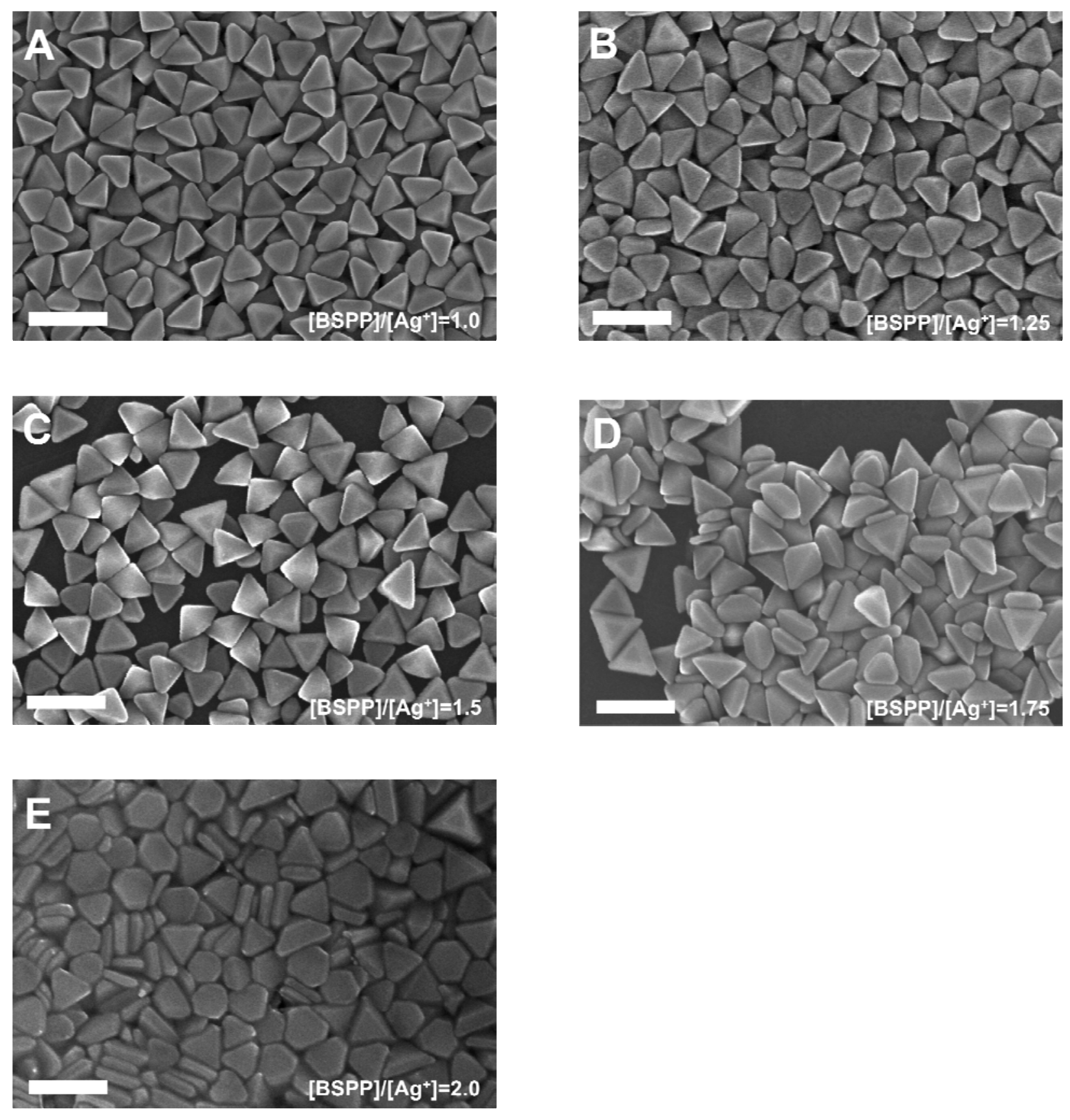

Figure S3. SEM images (scale bar: $200 \mathrm{~nm}$ ) of the silver nanoparticles synthesized at pH 10 with different $[\mathrm{BSPP}] /\left[\mathrm{Ag}^{+}\right]$ratios. 

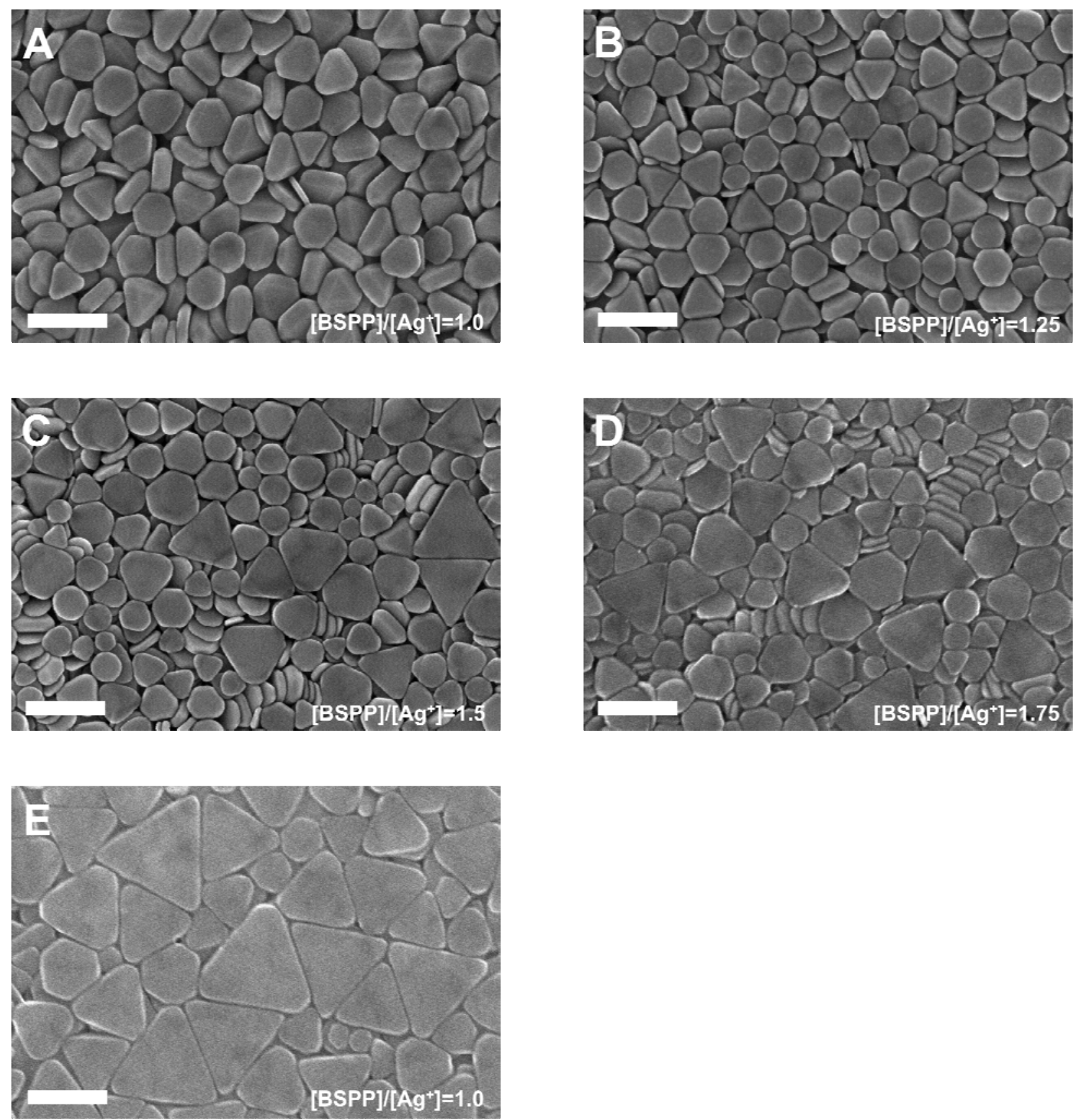

Figure S4. SEM images (scale bar: $200 \mathrm{~nm}$ ) of the silver nanoparticles synthesized at pH 9 with different $[\mathrm{BSPP}] /\left[\mathrm{Ag}^{+}\right]$ratios. 

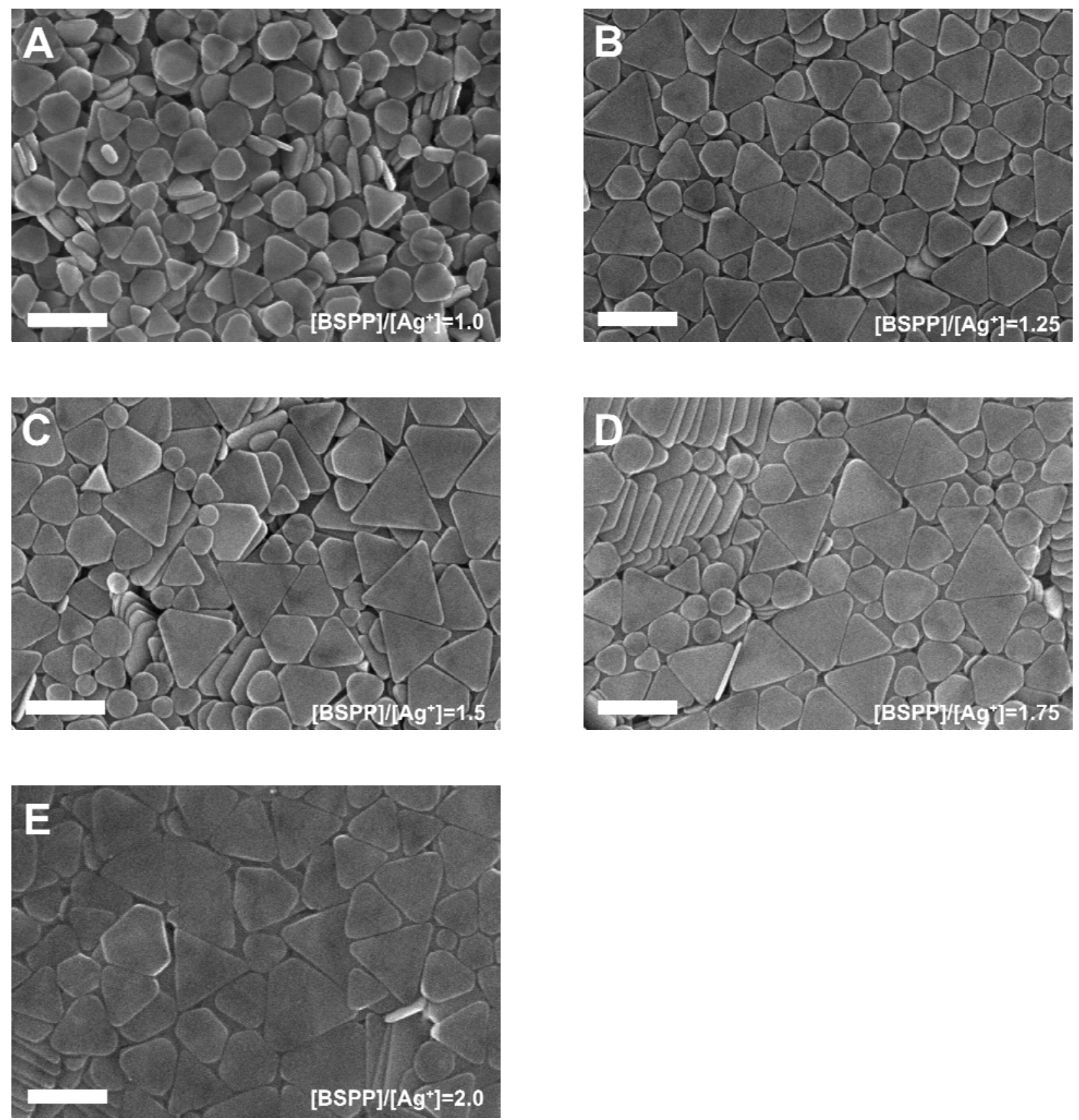

Figure S5. SEM images (scale bar: $200 \mathrm{~nm}$ ) of the silver nanoparticles synthesized at $\mathrm{pH} 8$ with different $[\mathrm{BSPP}] /\left[\mathrm{Ag}^{+}\right]$ratios. 

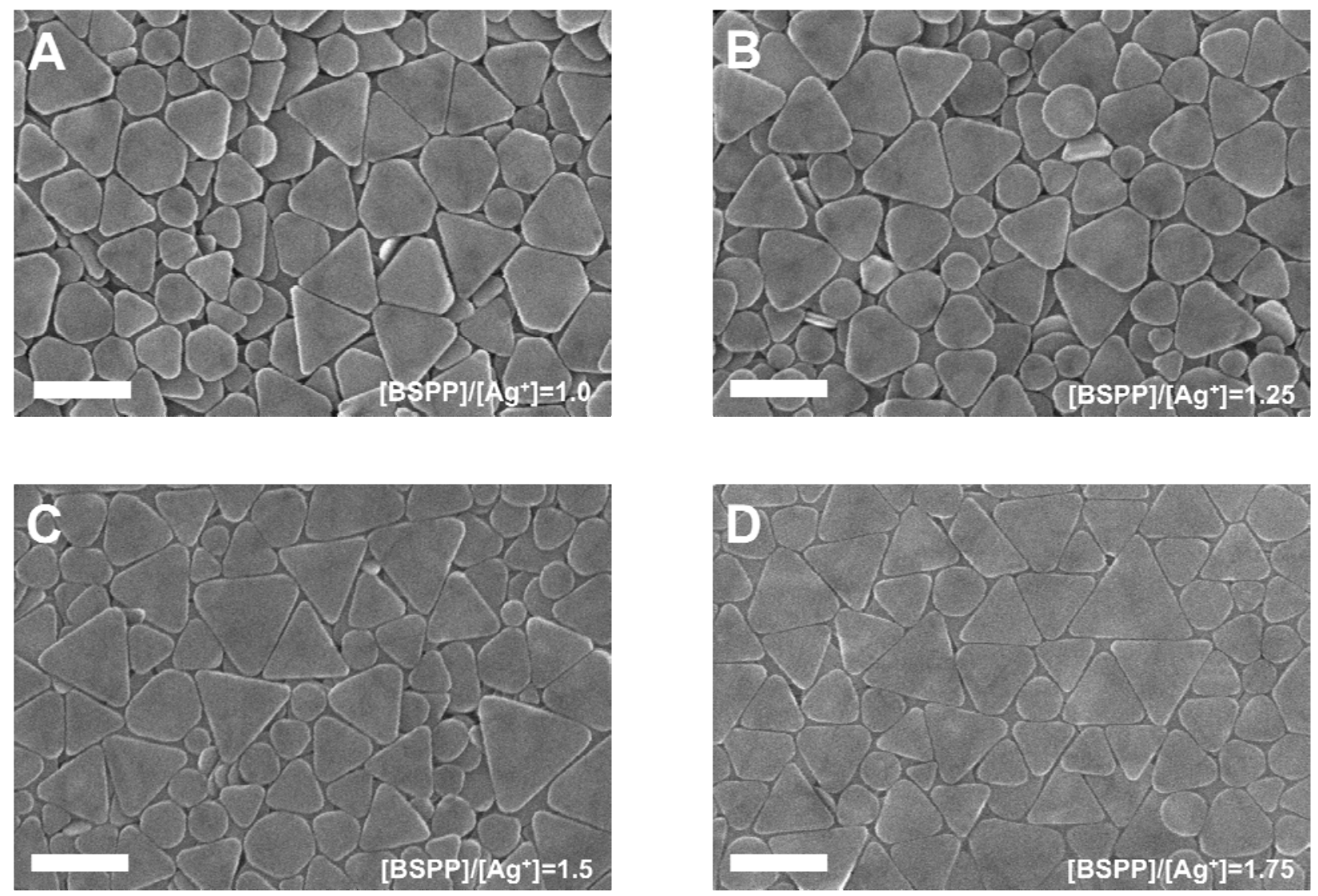

Figure S6. SEM images (scale bar: $200 \mathrm{~nm}$ ) of the silver nanoparticles synthesized at $\mathrm{pH} 7$ with different $[\mathrm{BSPP}] /\left[\mathrm{Ag}^{+}\right]$ratios. 

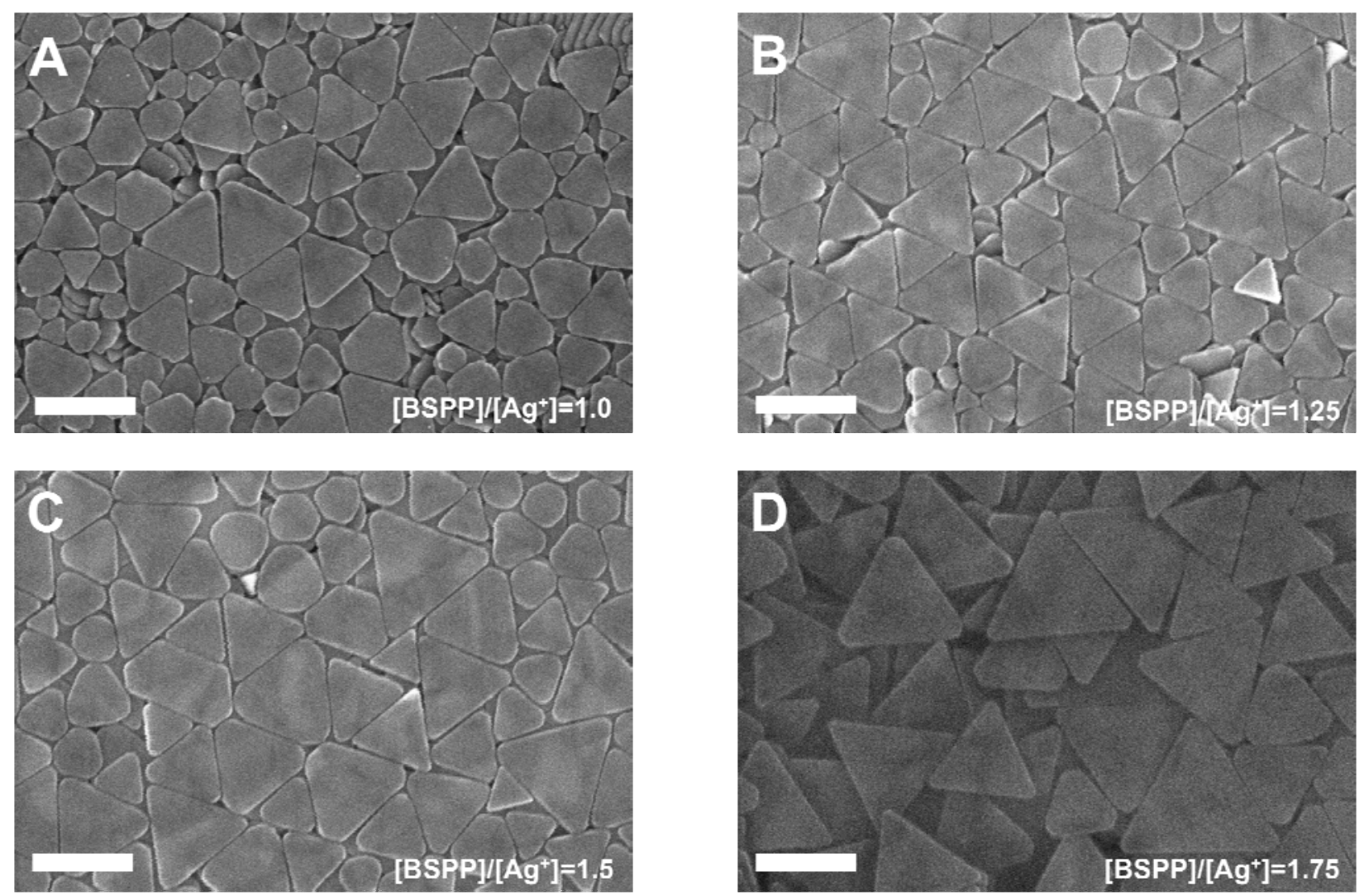

Figure S7. SEM images (scale bar: $200 \mathrm{~nm}$ ) of the silver nanoparticles synthesized at $\mathrm{pH} 6$ with different $[\mathrm{BSPP}] /\left[\mathrm{Ag}^{+}\right]$ratios. 

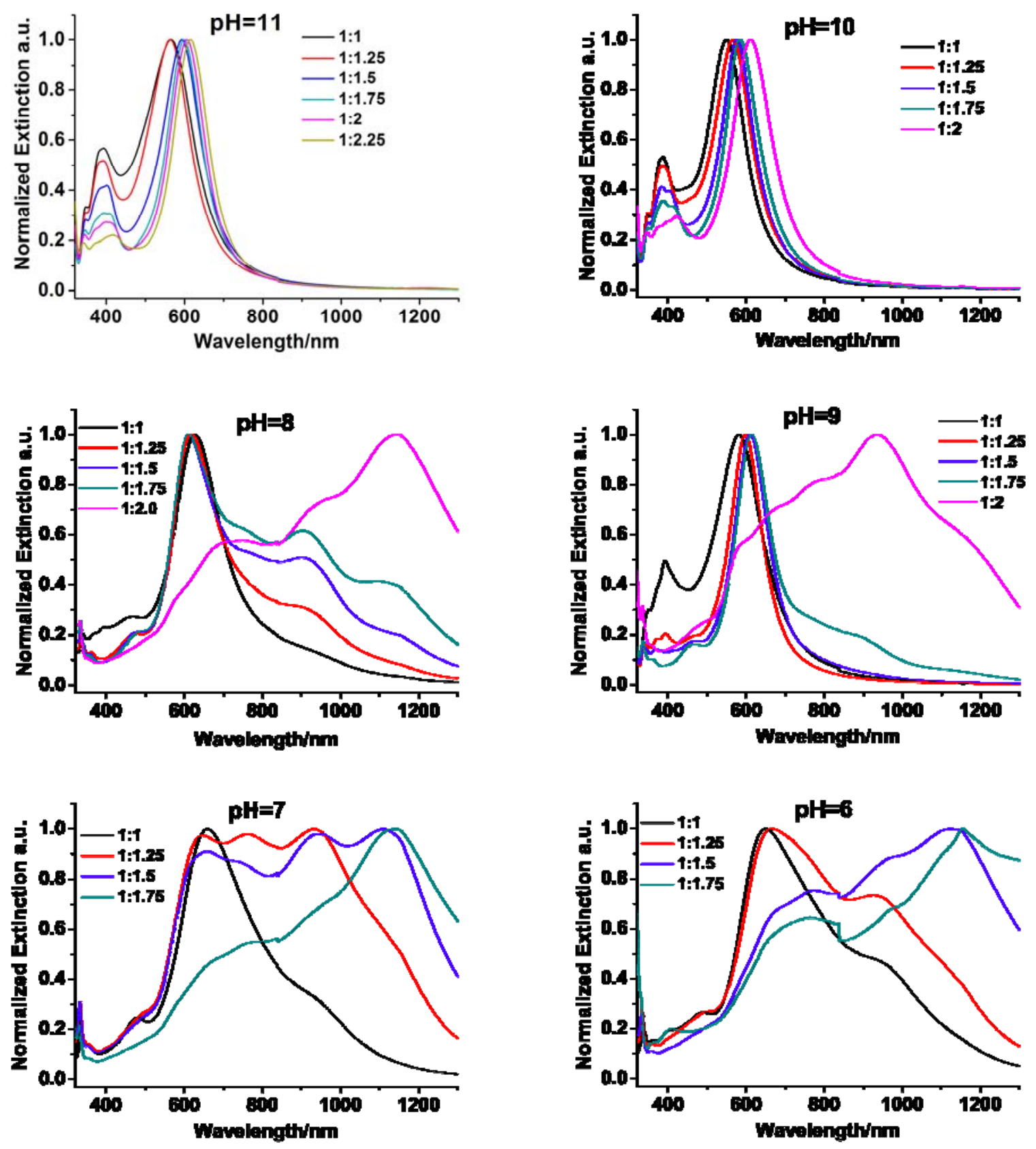

Figure S8. UV-vis spectra of the silver nanoparticles synthesized at different $\mathrm{pH}$ with different $[\mathrm{BSPP}] /\left[\mathrm{Ag}^{+}\right]$ratios. 


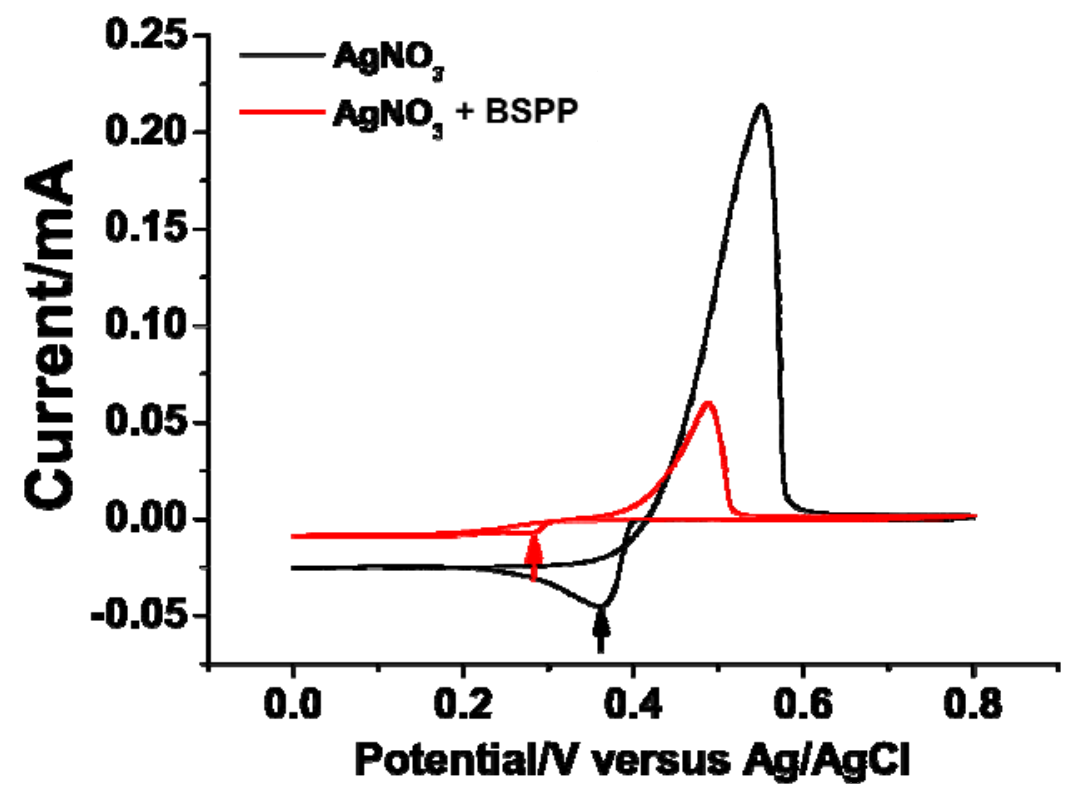

Figure S9. Cyclic voltammogram of an aqueous solution of $\mathrm{AgNO}_{3}$ and a solution containing an equimolar amount of $\mathrm{AgNO}_{3}$ and BSPP.

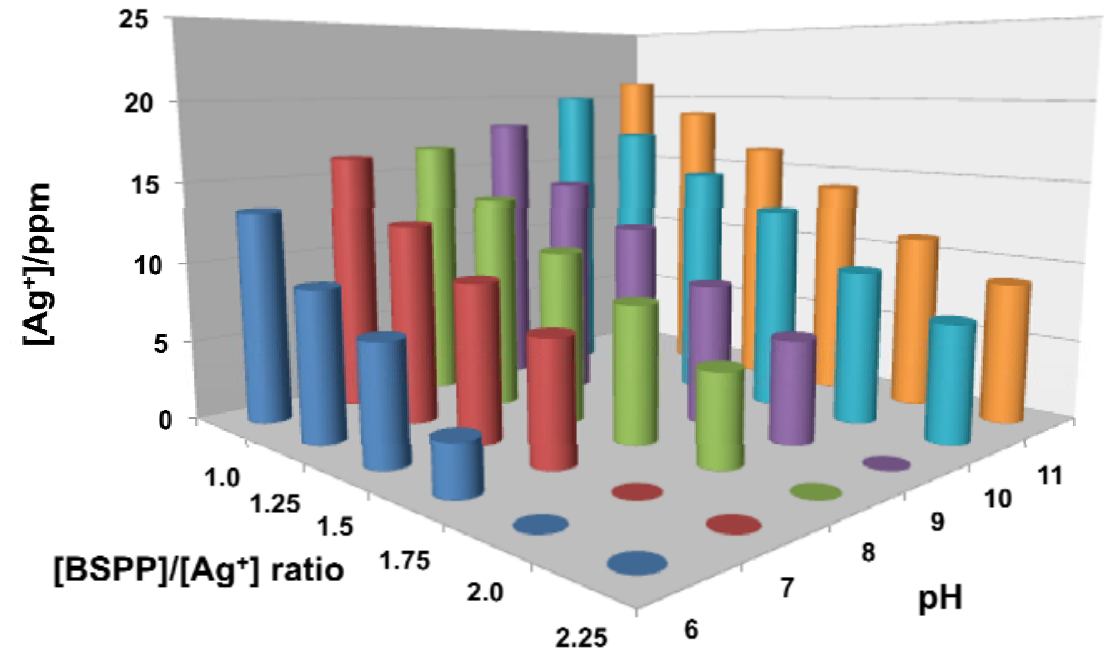

Figure S10. A 3-D representation of the reacted $\mathrm{Ag}^{+}$at different $\mathrm{pH}$ and $[\mathrm{BSPP}] /\left[\mathrm{Ag}^{+}\right]$ratios. 

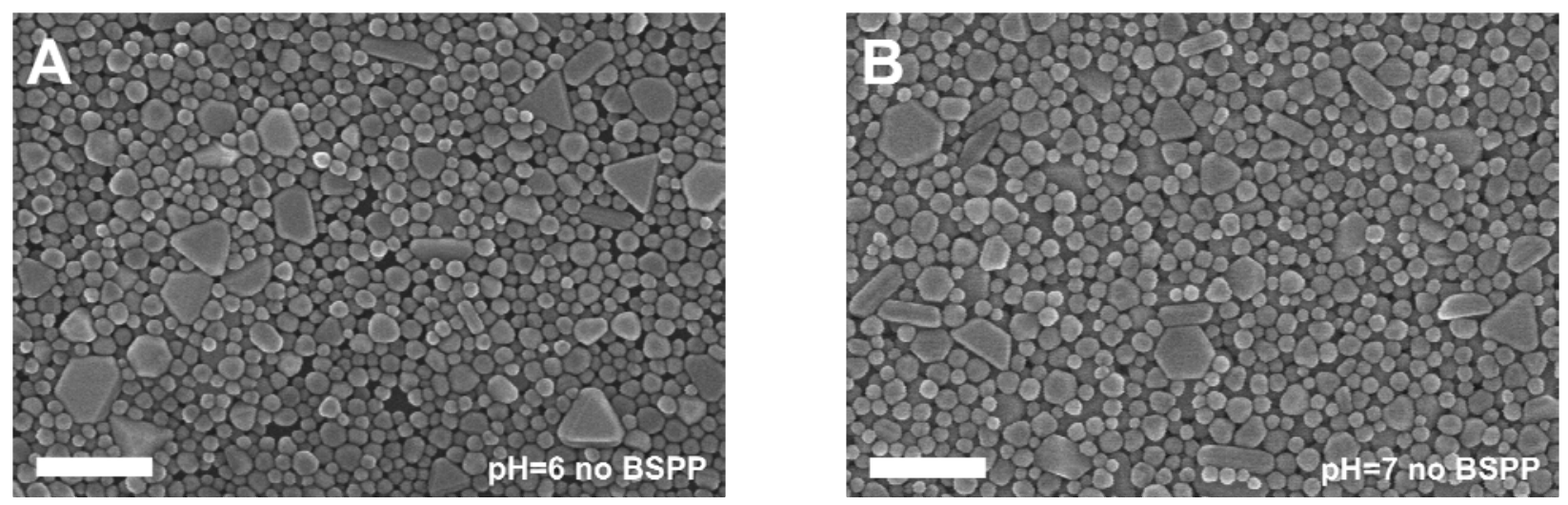

Figure S11. SEM images (scale bar: $200 \mathrm{~nm}$ ) of the silver nanoparticles synthesized at pH 6 (A) and pH 7 (B) without BSPP.

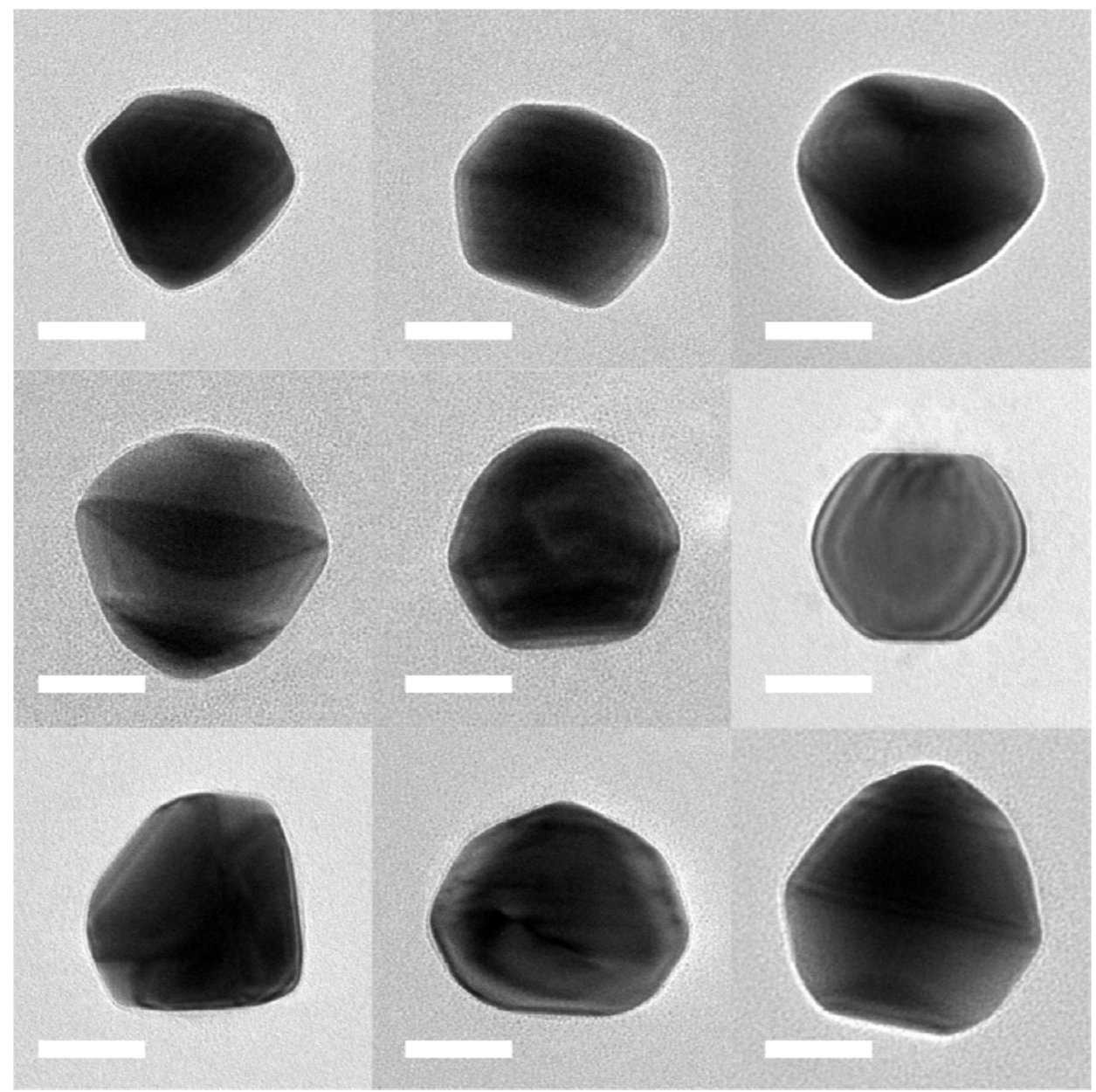

Figure S12. TEM images of (111)-faceted truncated bitetrahedra synthesized from reaction 8-0. (Scale bar: $50 \mathrm{~nm}$ ) 


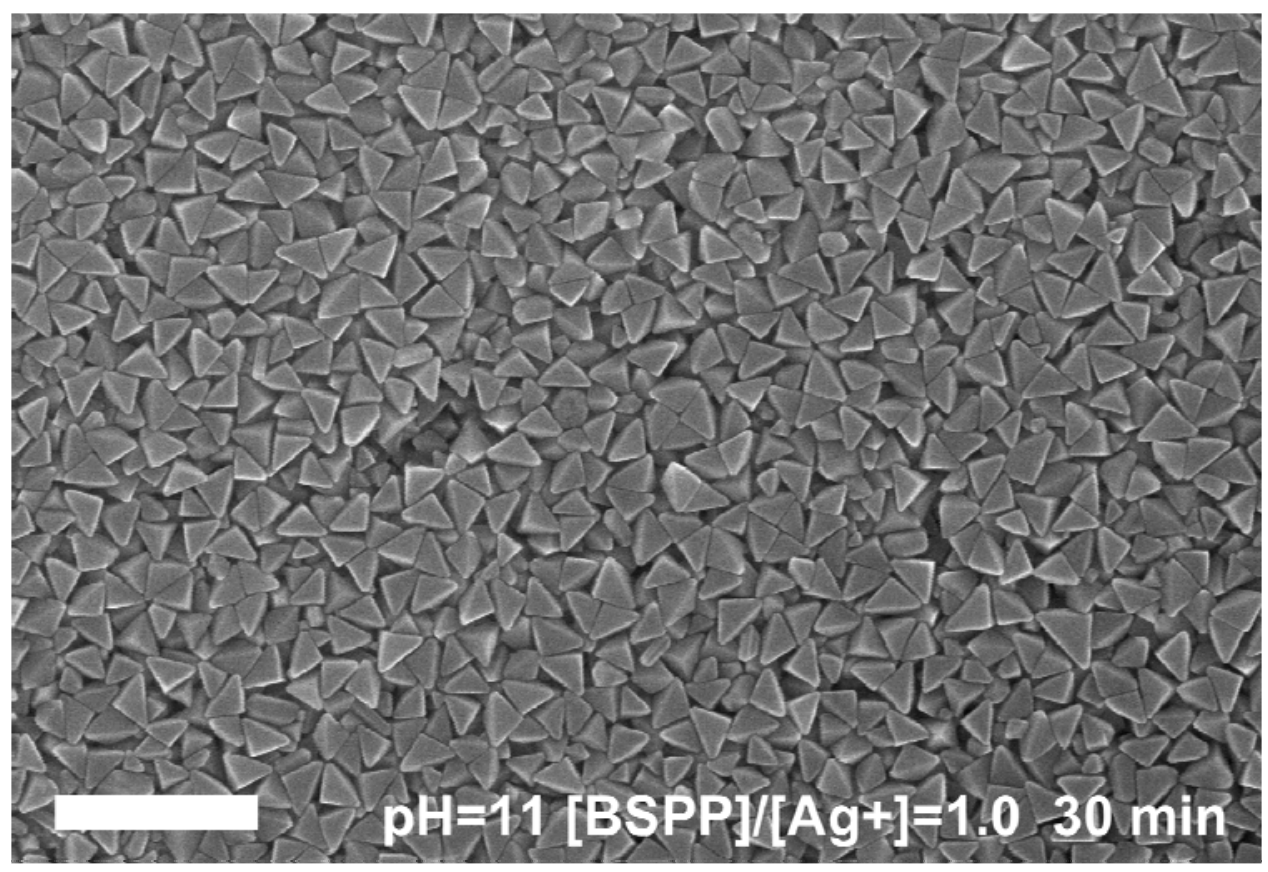

Figure S13. SEM image (scale bar: $400 \mathrm{~nm}$ ) of the silver nanoparticles synthesized in 30 min for reaction $11-1.0$. 